SMALL-GROUP LEADER ASSIGNMENT:

EFFECTS ACROSS DIFFERENT DEGREES OF TASK INTERDEPENDENCE

\author{
by \\ Kevin J. Basik \\ A thesis submitted in partial fulfillment of the \\ requirements for the degree of \\ Master of Industrial and Organizational Psychology \\ Virginia Polytechnic Institute and State University \\ COPYRIGHT JUNE, 1997
}

APPROVED:

Roseanne J. Foti, Chair

Jeffery D. Facteau

Gustafson

Sigrid B.

Date:

Keywords: Interdependence, Assignment, Leader, Task 


\title{
SMALL-GROUP LEADER ASSIGNMENT: \\ EFFECTS ACROSS DIFFERENT DEGREES \\ OF TASK INTERDEPENDENCE
}

by

\author{
Kevin J. Basik \\ Roseanne J. Foti, Chair \\ Psychology Department
}

\begin{abstract}
The use of teams and work groups in organizations has become increasingly more popular in the last decade. Within each of these groups, a leadership role must be filled in order for the team to achieve its task. This study posited that the method by which the leader comes into this role may have a direct impact on the group's performance and its perceptions of the group's interpersonal processes and efficiency, satisfaction with the group, satisfaction with the group output, and support for the leader. In addition, the influence of leader assignment was expected to change based on the level of interdependence required by the task. One hundred forty-eight subjects were assigned to one of four conditions in a $2 \mathrm{X} 2$ design (appointed vs. elected leaders X high vs. low interdependence task), and were asked to fill out a questionnaire upon completion of their task. Results found that the higher level of interdependence was significantly related to more favorable ratings of Perceived Group Efficiency $(\underline{F}=6.89, \underline{p}<.05)$ and Satisfaction with Group Output $(\underline{F}=7.69$, $\mathrm{p}<.05)$. Possible limitations and future research opportunities are addressed.
\end{abstract}




\section{ACKNOWLEDGEMENTS}

The first note of thanks has to be to my ever-patient and loving wife, Jennifer. I know it wasn't easy going to work when I got to sleep in, but believe me, I'm sure the worm will turn. Seriously, all my efforts personally and professionally have your happiness as a motivator. I love you with all my heart and thank you for your support as I worked on this big, nasty document.

I would also like to thank my family for their support and constant ribbing about my not having "a real job". Without their not-so-subtle challenges about my schedule, I might have played more golf and wasted the Air Force's money. After 2 years of work, I am convinced that no one in my family yet has a clue as to what I/O Psychology is, and I look forward to many conversations where you all look me in the eye and mutter, "What the hell was your degree in again?". Believe it or not, by explaining it all to you, it kept me motivated, so thank you.

My friends here at Tech will forever be dear to me. Tim, Rachel, Melissa, Dan, Todd, Heath, K Bradley, (Superstar, Hotshot, Ace, Toughguy, Skippy, Maestro, and RockStar, respectively), as well as Wendy, JeanAnne, Theresa, Nicki, Dan, Josh, Jason, Chuck, and everyone else I have just forgotten, I honestly hope to keep in touch and follow the success of each of your careers.

A special thanks to Roseanne Foti for being a wonderful advisor and putting up with me as I trudged through this thesis. I consider you a friend and a mentor. I would also like to thank Jeff Facteau (a Facteauvian reference to a Simpsonian tangent is always a good idea, DOAH!) and Sigrid Gustafson (finally someone to straighten out the Army!). You have taught me more than you know, and I am proud to have gotten to know you both. Your help with my thesis has beens greatly appreciated.

Finally, to my dear Gayle Kennedy. You made it a pleasure to come into the department every day. Please know how much I appreciated all you did for me. Its so refreshing in this Politically Correct world to find someone who still gives hugs! (That goes for you too, Sigrid). My best wishes to you all, and thank you for your friendship. 
Dedicated to my beautiful and loving wife, Jennifer. 


\section{TABLE OF CONTENTS}

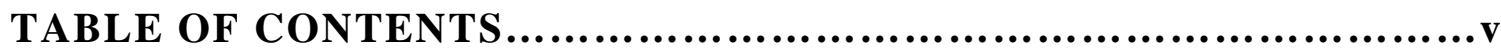

LIST OF TABLES.........................................................vii

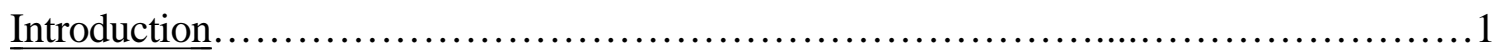

Literature Review................................................................

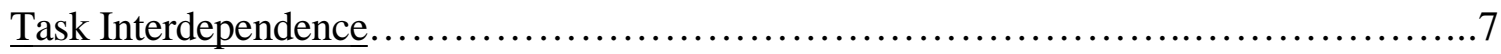

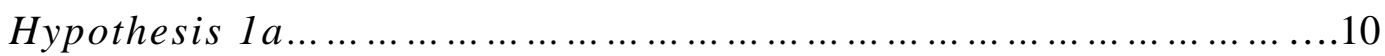

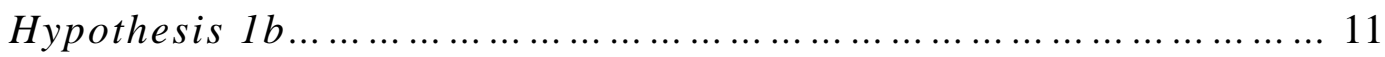

Leader Assignment Strategies.......................................................

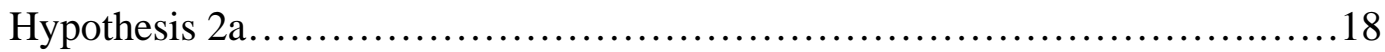

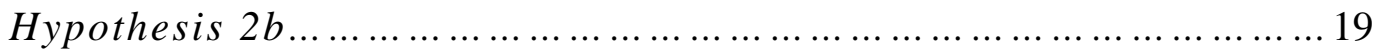

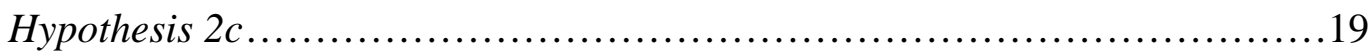

Interaction Effects................................................................ 19

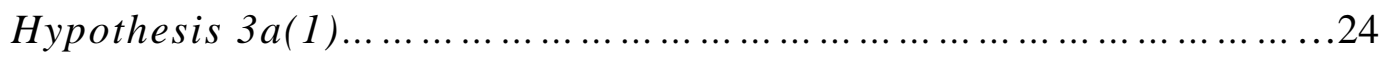

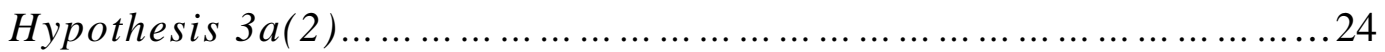

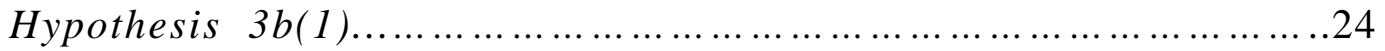

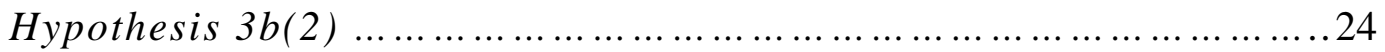

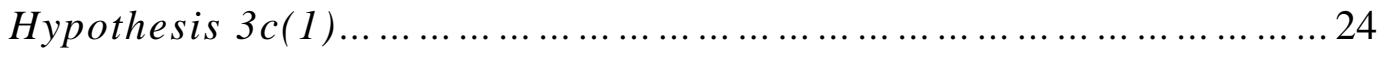

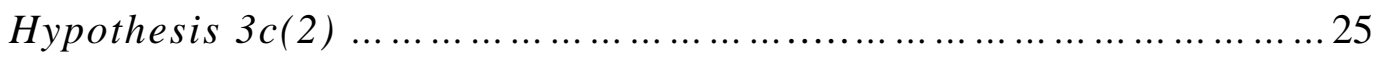

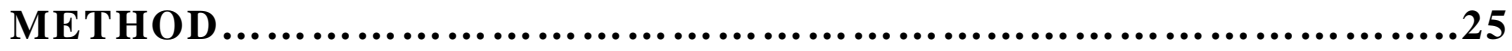

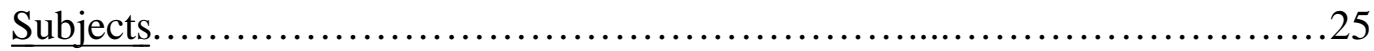

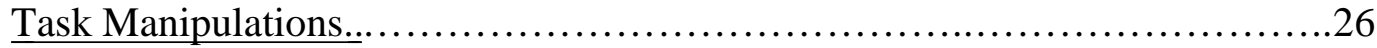

High Interdependence ............................................27

Low Interdependence .............................................27

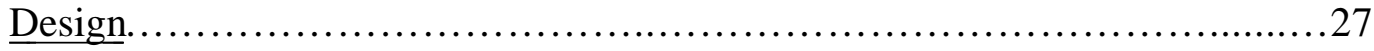

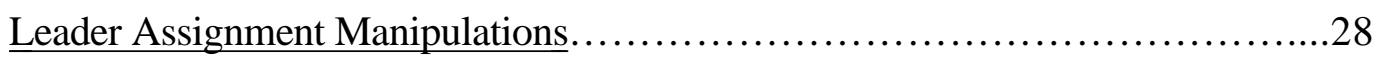

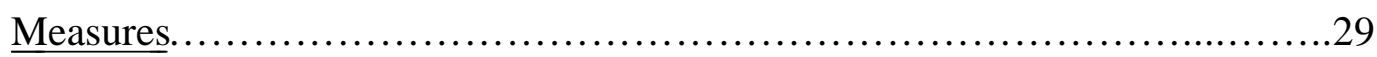

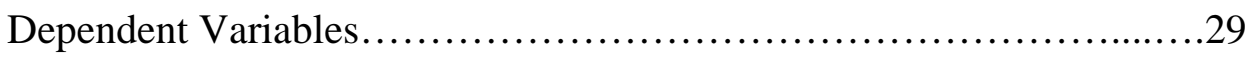


Manipulation Checks.............................................31

Confounding Variables........................................32

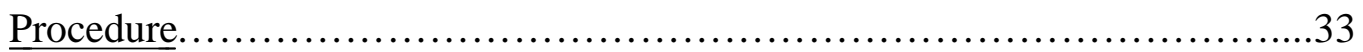

High Interdependence Task......................................33

Low Interdependence Task......................................34

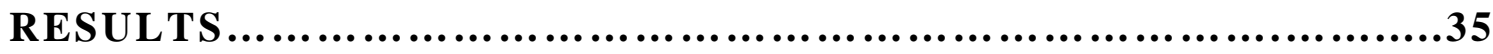

Manipulation Check................................................ 37

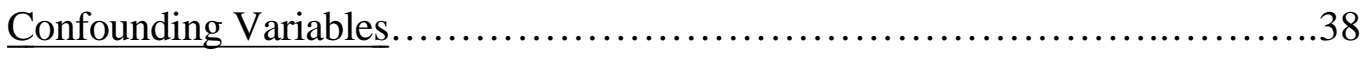

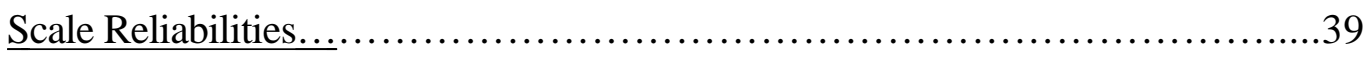

Hypothesis Testing..............................................41

Main Effects for Interdependence................................42

Main Effects for Leader Assignment................................42

Interaction Effects...........................................43

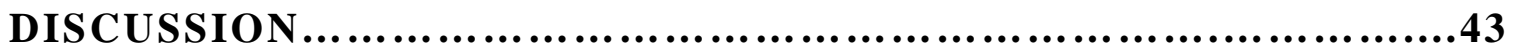

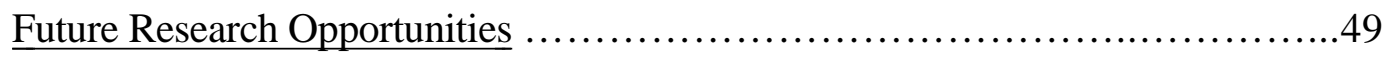

REFERENCES ......................................................52

APPENDIX A: Instructions for Job Placement Task (High Interdependence)

APPENDIX B: Instructions for Manufacturing Task (Low Interdependence)

APPENDIX C: Post Task Questionnaire

APPENDIX D: Tables

VITA. 


\section{LIST OF TABLES}

TABLE 1: $\underline{\text { ANOVA Results for Cell Standard Deviation Comparisons }}$

TABLE 5: Group Level Correlation Matrix (IVs, Performance, Scales, Confounding

$\underline{\text { Variables) }}$

TABLE 3: $\underline{\text { Scales Reliabilities }}$

TABLE 4: Cell and Total Means, Standard Deviations, and Number of Groups

TABLE 5: ANOVA Results for Mean Comparisons 


\section{INTRODUCTION}

Work groups are critical to organizational survival in the late $20^{\text {th }}$ century and have been described as the "building blocks for getting work done" (Goodman, 1986). They offer organizations an effective way to coordinate across organizational boundaries in order to solve problems and increase employee commitment (Shonk, 1992). Since the studies by Trist in the 1950's demonstrated the effectiveness of work groups (in coal mines), whole organizations such as Proctor \& Gamble, Caterpillar, Boeing and General Foods (for a more extensive list, see Fisher, 1993) have successfully re-engineered their structures to support a group or team philosophy (Tjosvold, 1991; Shonk, 1992). But despite the rise in popularity and application, there remains a problem in both defining and truly understanding the dynamics of group interaction.

Perhaps McGrath (1984) best articulates the many dimensions of groups in society. For the interest of organizational application and this study in particular, we shall focus on the work-related groups, which McGrath labels "work teams". This small group is a deliberately designed social unit whose members (incumbents) interact with each other and are highly interdependent in terms of organizational rules (p. 7). Shaw (1981) adds the requirement of reciprocal influence among members, and Shea and Guzzo (1987) require that the members see themselves, and are seen by others in the organization as a group. Comparison across groups is often difficult, however, because these social groupings of individuals often vary on many dimensions. For example, how a work group is defined might depend on the degree of autonomy, time constraints, size, level of 
interdependence, number of goals/tasks, nature of the tasks, presence of a formal leader, familiarity group members, or some other dimension (Shonk, 1992; McGrath, 1984; Hughes, Ginnett and Curphy, 1993; Wageman, 1995). Many studies do not take the time to operationally define their group dimensions, thus creating inconsistencies which make integrating the literature quite frustrating. The definition of a group has emerged rather clearly, but beyond that, much variation exists. Some researchers draw a clear distinction between "groups" and "teams," whereas others use the terms interchangeably. For example, Hughes, Ginnett and Curphy (1993) suggest that teams are different from groups in that teams have a stronger sense of member identity, common goals or tasks, and higher levels of task interdependence, whereas Stewart \& Manz (1996) suggest that any small group is a team. Terborg, Castore, and DeNinno (1975) argue that a group becomes a team only after working together for some time. Likewise, group designs are often described as unique or used synonymously in an almost random fashion. Titles of groups, work-groups, autonomous/semi-autonomous work-groups, quality circles, task forces, teams, decision-making groups, and so on, have been defined and used inconsistently across a number of studies.

For the purpose of this study, we will define "groups" as the broadest category of "social aggregates that involve mutual awareness and mutual interaction" (McGrath, 1984). "Work groups," then, are the deliberately designed subset of groups which 1) have boundaries, interdependence, and differentiated member roles, 2) have one or more tasks to perform, tasks for which members have collective responsibility, and 3) operate in an 
organizational context with interaction from outside entities (Hackman, 1990). Therefore, designs such as semi-autonomous work-groups, quality teams/circles, task forces, selfdirected work teams, self-managing teams, decision groups, suggestion teams, process action teams, and leaderless groups will all fall under this definition of work groups.

Two types of group designs are very popular in today's applications: leaderless (autonomous, self-directed, self-managing) work groups and traditional groups with assigned leaders (mentors, coaches, facilitators, etc.). Again, however, some confusion exists in defining what constitutes a leaderless group (as is evidenced by the common managerial concern of "how to lead/manage a leaderless/self-managed group"). Some of these work groups have assigned team leaders whereas in other studies or organizations, the groups are truly leaderless until an informal leader emerges from the group (Baird \& Weinberg, 1981). This leadership assignment issue needs to be addressed and clarified, considering as many as $40 \%$ of all U.S. employees are expected to be working in selfmanaged teams by the year 2000 (Stewart \& Manz, 1996). Both leaderless and formal leader designs have been researched and organizationally utilized with positive results, but no contingency has been presented to define when an organization should use one or the other (Pearce \& Ravlin, 1987; Fisher, 1993). Groups that are designed to be truly leaderless, and which expect no leader emergence, are rare. Such groups may offer the benefits of equally balanced status, authority and responsibility, but often fall short when a specific task needs to be accomplished (Counselman, 1991). In most organizational settings, a leadership role must be filled within the group in order for the group to be 
effective. Today, many organizations have learned that "groups are good" (if implemented properly), but the type of group, and the appropriate matching leader-group structure to implement should be a function of what task the group is being asked to do.

Within the group structure, one of the most critical dynamics is that between the group and the leader. Leaders have an important effect on a group's development of a stable structure, and those groups which are unable to develop and promote a differentiated leader-follower role structure will be unable to perform tasks effectively (Bass, 1990). With all the effort that is commonly exerted to screen, select, and train a leader, it seems unreasonable to start off the whole process by ignoring the potential impact that the leadership assignment decision may have on the group functioning. The assignment or emergence of the leader role may have a significant influence on group members' perceptions of the group dynamics; these perceptions can in turn affect many task outcomes. With much of the inconsistency in the results of group research pivoting on the formal/informal (emergent) leadership issue, it seems essential to determine if any variance can be explained by this decision. Perhaps organizations and researchers have been ignoring a simple, yet important early decision point when implementing or studying groups.

This study will investigate the effects of leader assignment across different task types. Ideally, the task being asked of the group may provide a contingency that determines the ideal leader assignment process. As explained by McGrath (1984), the task situation is a critical factor which one must take into account in order to understand 
and predict group interaction. The level of task interdependence, which is the degree to which the task requires communication or dependence on other group members, was selected for several reasons. First, this is a well-researched area, with clearly distinguishable levels of manipulation (Fry, Kerr and Lee, 1986; Saavedra, Early and Van Dyne, 1993; Johnson, Johnson, Ortiz and Stanne, 1991; Van de Ven, Debelcq and Koening, 1976). Second, it was chosen for the sake of ecological validity (a common concern with regard to lab-based group research). The manipulation of task interdependence can reflect group structures which are realistically found across organizations. This study will investigate applications to "task groups" in particular, as the task group design (described by Hackman, 1990) is very similar to how experimental groups are arranged and conducted (members do not normally work together in the organization, the group has a clearly defined task, and there is a limited amount of time the group will be assembled for the task). Task interdependence is a realistic and common feature on which work groups often vary. It has been shown to affect the level of group cooperation, group productivity (Shea \& Guzzo, 1987), and the nature of interpersonal interactions among work group members (Saavedra, Early and Van Dyne, 1993), thus suggesting that the leader assignment issue of interest here may have direct implications for organizational effectiveness.

In this era, as organizations continue to streamline in order to reduce costs and remain competitive, the consequence is that "more has to be done with less than before." Groups and teams have recently been used to provide the competitive advantage to meet 
this challenge, but successful group implementation requires an understanding of the relationships among the critical components of the group system. In particular, the method by which a leader assumes his or her pivotal role and the nature of the task will determine the direction, opportunities, and limitations of the group.

\section{Literature Review}

Those who create and lead work groups must develop contexts which increase the likelihood of effectiveness. Hackman (1990) suggested that the effectiveness of any work group should be evaluated on three criteria: 1) whether the product or output of the group meets or exceeds the client's standards for quantity, quality, and timeliness; 2) the degree to which the group processes enhance the capabilities of the group members working together; and 3) the degree to which the group experience leads to the growth and well being of the members. Unfortunately, the factors which influence effectiveness come in what Hackman describes as, "complex tangles which are often as hard to straighten out as the backlash on a fishing reel" (1990). Untangling these factors requires attention to the task characteristics as well as to the structure of the group.

The effectiveness of a work group is largely dependent on the match between a group's structure and its technology and environment (Bettenhausen, 1991; Goodman, Ravlin, and Argot, 1986). Work groups are brought together to perform some task, whether short or long-term, and understanding the requirements/restrictions that this task introduces is critical when designing such a group. Traditional variables of organizational 
theory, such as task interdependence, have a profound impact on group interactions and performance (Bettenhausen, 1991).

As the degree of interdependence changes, so too do the coordination requirements for coordination among the group members. The effective work group needs to be established with consideration for the nature of work flow of the task, as it defines how effort, resources, and information are to be coordinated. Ignoring or improperly addressing this issue may have a critical impact on intragroup processes.

\section{Task Interdependence}

Task interdependence is defined as the degree to which group members must rely on one another to perform their tasks effectively, given the designs of their jobs (Saavedra, Early and Van Dyne, 1993). Interdependence is seen as a structural characteristic of work, but tasks can be designed to be performed at different levels of interdependence (Wageman, 1995).

Thompson (1967) identified the processes by which task components can be combined into a whole, defining the levels of task interdependence most often seen in groups. The lowest level of task interdependence is "pooled interdependence," in which the whole task is performed separately by the members without task-relevant interaction. Performance for the group is simply the sum of the individual performances. "Sequential interdependence" is traditionally thought of as an assembly line process. One group member must act before another can act. At this more advanced level of interdependence, 
group members have different roles and complete only a portion of the task. The next highest level of interdependence is "reciprocal", in which the group members generally have specific roles and subtasks in which they are the "experts," such as with a surgical team. Person A's output becomes person B's input and vice versa, and the sequence of the steps in performing the task is very flexible (Saavedra et al., 1993). The final and highest level of task interdependence, (which was added to Thompson's hierarchy by Van de Ven, Delbecq and Koening in 1976), “team interdependence," represents the task design often seen in the popular self-managing/autonomous/self-directed teams (work groups) or many organizations today. This task requires mutual (or what Van de Ven et al. call "simultaneous") interaction among group members to diagnose, problem solve, and implement a process to complete the task. Members have the autonomy to define their own roles, jobs, and the nature of their interaction. Examples of the team interdependence arrangement are group therapy sessions or a traditional "think tank" (Van de Ven et al., 1976).

Van de Ven et al. (1976) suggested that as task interdependence increases, so too does the requirement for certain coordination mechanisms. Too much or too little orchestration of action among the group members can bring about ineffectiveness (Shea \& Guzzo, 1984). Obviously, the nature of the task has clear implications for the appropriateness of certain performance strategies. Therefore, the efficiency by which a group or team is able to coordinate its social and task-related interactions across different task types is imperative to the ultimate effectiveness of the group. Wageman (1995) 
found that higher levels of interdependence (equivalent to reciprocal or team interdependence) result in higher cooperation norms, higher quality of group process, and higher general member satisfaction. Saavedra et al. (1993), however, found some mixed results, in that sequential task interdependence resulted in significantly lower performance (quality and quantity) than all other conditions, reciprocal interdependence resulted in the highest conflict, and group member ratings of the group strategy were significantly higher in the reciprocal and team conditions.

The results for the pooled and team levels of interdependence conditions (in the Saavedra et al., 1993) are, however, supportive of the arguments of the current study. In particular, team level interdependence (versus pooled interdependence) was associated with significantly higher quality, quantity, and group strategy scores, as well as with lower ratings of intragroup conflict. Cheng (1983) demonstrated that as task interdependence increased within academic, industrial, and government organizations, the demand for coordination also increased. In addition, he found that task interdependence also moderated the relationship between coordination and output quality and quantity.

Hackman's criteria for group effectiveness also require that attention be directed to the social aspects of the group, thus addressing satisfaction and potential for future or continued group performance issues. Past research has shown, for example, that task interdependence moderates the relationship between group cohesion and performance (Gully, Devine, and Whitney, 1995), and interdependence was hypothesized by Shea \& Guzzo (1987) to be related to group potency (similar to group self-efficacy) and 
ultimately to performance. Also, high task interdependence has been associated with higher cooperation norms, quality of interpersonal processes, learning, and work satisfaction, whereas lower task interdependence (when matched with individual outcome interdependence) has been associated with greater work motivation and stronger effort norms (Wageman, 1995). Interestingly, it was shown that the level of task interdependence actually influenced the perceived level of outcome interdependence experienced by the members, suggesting that the task (or work design) can actually shape how group members experience their rewards and how those rewards impact their performance (Wageman, 1995). All of this taken together suggests that increased levels of task interdependence require more coordination and a positively perceived increase in member social interaction, ultimately leading to more favorable effectiveness outcomes.

Based on this research, it is expected that perceived effectiveness will be greater for groups with higher levels of task interdependence than for groups with lower levels of task interdependence. Effectiveness criteria will be based on those established by Hackman (1990) and mentioned earlier.

Hypothesis 1a) Higher task interdependence will be associated with higher scores on quality of interpersonal processes and efficiency ratings compared to the scores generated in a low task interdependence condition. 
Hypothesis 1b) Higher task interdependence will be associated with higher ratings of satisfaction with the group and its output, and with higher support for the leader in comparison to the scores generated in a low task interdependence condition.

\section{Leader Assignment Strategies}

Despite the often confusing and deceptive titles assigned to very autonomous work groups, some leader role is usually present. Although there are unique examples in which leaderless or self-managed groups truly have no leader or supervisor, these examples comprise either taskless groups, such as psychotherapy groups (Counselman, 1991) or organizational "pet" projects, such as the successful 3-year Mountain Bell Hotel Billing Information System (Taylor, Friedman, and Couture, 1987). In general, however, some leadership role needs to be filled and is filled in one of two ways: delegation or emergence (Baird \& Weinberg, 1981).

Counselman (1991), ironically, documented a number of true leaderless psychotherapy groups that failed, often because there was no leader-provided direction. Researchers and practitioners agree that a group's ability to develop a differentiated leader-follower role structure will result in its ability to engage in effective task performance (Tjosvold, 1993; Bass, 1990). Until this role structure is determined, the group will experience a period of confusion and decreased productivity (Tuckman, 1965). Eventually, management may step in and introduce a leader to allow the team to progress to the next stage of its life cycle (Laiken, 1994). The leader who is assigned, or the 
individual who emerges from within the group, has a direct impact on the members' interest in the goal of the task, as well as on the potential overall efficiency and effectiveness of the group (Bass, 1990). Leader assignment is an area of research that has been basically ignored, despite the profound impact this simple decision may have on the group performance.

Most work groups will have a leader assigned by the organization, and the role is often filled by an individual who has recently been a manager. This procedure introduces an important practical point. Typically, as organizations move to the use of groups or teams, the team concept (whereby many tasks/responsibilities of the managers are now handled by the team) must be strongly supported from the top down as well as from the bottom up if the program is to succeed. The employees need to feel that this new "empowerment" is not just lip service. In this respect, it seems almost self-defeating for an organization to use as the team leader (albeit an external leader or facilitator) a person from the earlier system. Often, as the organization's new era dawns, the former managers are worried that the employees are not ready for the new responsibility and accountability, and the employees are worried that the managers are not ready to handle the loss of power. From the perspective of the work group itself, the leadership process is affected by the agreement among group members as to who should fill the leadership role (Bass, 1990).

Such subtle impacts of why emergent leaders would be expected to improve group perceptions, performance, and effectiveness are particularly appealing. Baird (1981) 
describes an interesting behavioral approach for explaining how an individual emerges as a leader. Contrary to the idea of "the cream rising to the top," Baird suggests that through interaction during early developmental group stages, the leader is the one who simply survives the elimination process. Those who are least likely to participate in interactions, or those whose inputs are too annoying or dramatic, for example, are the first ones out of contention. The appearance of low ability or intelligence is the second way to be eliminated. In an appointed leader situation, this process is circumvented all together. The group may get (or perceive they have gotten) someone in the leader role who would have not been the "last one standing" had things followed their natural course. (For the purpose of this study, however, it is important to understand that the perceived legitimacy of the appointed leader is posited here to be independent of the ability of the appointed leader. In fact, steps will be taken to control for such ability, in order to ensure that both elected and appointed conditions receive leaders who have emergent leader abilities.)

In a similar manner, DeSouza and Klein (1995) make a reasonable argument regarding the legitimacy of the individual who is assigned or emerges into the leader role. They suggest that the emergence process provides the leaders with legitimacy in the eyes of the other team members, whereas a formally appointed leader's legitimacy does not originate from these group member perceptions. A type of social exchange process takes place between an emergent leader and the group, where the leader is expected to produce more favorable outcomes for the group in return for being acknowledged as the leader 
(Hollander, 1985 as cited by DeSouza \& Klein, 1995). However, the appointed leader may not have the support of perceived credibility with the other group members, despite his or her personal attributes.

The legitimacy argument is supported in a study by DeMatteo, Dobbins, Myers and Facteau (1996), in which leaders were assigned to groups based on either a merit-based or a preferential standard. Although this study was investigating the effects of affirmative action policies on follower perceptions (i.e., all the assigned leaders were women assigned to a male group), the implications are important for any group situation in which the selection of the leader may be interpreted by the followers. DeMatteo et al. found that when leaders were assigned using a preferential method, they were perceived as less prototypical, less effective, and more likely to be considered for replacement by the followers. Any appointed leader has been removed from the critical role development process and is susceptible to perceptions of non-merit-based selection. Hollander (1992) suggested that emergent or elected leaders (one might assume that the elected leader has "emerged" to win the election) have more legitimacy in the eyes of the followers, as a result of the election process which "creates a heightened psychological identification with the leader." Likewise, Salancik and Pfeffer (1978) proposed that those who elect a leader become personally committed to the outcome, and as a result of this commitment, satisfaction with work may increase, no matter what specific changes are made by the leader. 
This legitimacy can play an important role in shaping the followers' perceptions of the leader, as well as in ultimately influencing group performance (Ben-Yoav, Hollander and Carnevale, 1983). In the same respect, for work groups such as task forces which often bring together (for a limited amount of time) individuals who do not ordinarily work together, the introduction of an assigned leader may disrupt the group development process, causing resentment or lack or agreement among members regarding the leader. Acceptance of the leader has been shown to correlate with cohesion (Bass, 1990), which has ultimately been related to performance (Gulley, Devine and Whitney, 1995). Other studies have also documented that leaders have more authority when group members have participated in the leader selection process (election) than when the leader is appointed (see Greenberg \& Folger,1983). This issue of perceived legitimacy of the leader may have significant implications for the entire group process.

However, few organizations and studies have identified and differentiated the roles of the team leader (which is of interest in this study), and the "external" leader (facilitator, coach, etc.). These leadership roles have different requirements and impact group processes differently, but they are often used synonymously in the literature. Manz \& Sims (1987), for example, investigated the difference between the behaviors of the internal team leader and the more external team coordinator. Whereas the team coordinator was perceived to promote self-management, the team leader was seen as an additional team member who facilitated the group's organization, coordination, and resource acquisition. Although this study did address the election/appointment issue, the leader roles were 
very different (but not investigated as such). A few studies have come somewhat closer to a true comparison. For example, an interesting study by Seers, Petty and Cashman (1995) evaluated team-member exchange quality under conditions of traditional group management (high status leader appointed) and team-based management (internal group member elected as leader). The group in the team condition, with the elected leader, experienced increased group-member exchange, whereas more traditional groups (appointed leader), experienced a decline in reciprocation and lower exchange quality. The increased group-member exchange for the team (elected leader) condition was also associated with gains in group production efficiency.

Largely, the research literature lacks investigation of group-level outcomes for an appointed leader versus an emergent leader condition. On an individual level of analysis, previous studies have found that emergent leaders (versus appointed leaders) are held to a higher standard, granted more latitude in action, and are not allowed to act selfishly when distributing group gains (DeSouza \& Klein, 1995). Other studies (e.g. Rogelberg, O'Connor and Bachiochi, 1996) have focused on the group-level outcomes strictly for emergent versus non-emergent group leaders, ignoring altogether the appointed leader condition. In some of these cases, as expected, groups with emergent leaders outperformed those without emergent leaders.

Emergent leadership has been shown to be possibly more beneficial than formal (appointed) leadership. The research strongly supports the positive outcomes associated with emergence and has identified many characteristics of those most likely to emerge as 
leaders. Ability, self-monitoring (Zaccaro, Foti and Kenny, 1991; Cronshaw \& Ellis, 1991; Garland \& Beard, 1979), dominance (Hegstrom \& Griffith, 1992; Lord, DeVader and Alliger, 1986), masculinity (Eagly \& Karau, 1991; Lord, DeVader and Alliger, 1986), intelligence (Hollander, 1978), and other traits have been related to leader emergence. Emergent leaders have also been shown to provide rewarding interactions to group members (Snyder, 1987), to express more positive, approving behaviors (Baird, 1977), to use a higher frequency of orientation statements (Knutson and Holdridge, 1975), to rate higher on giving approval and agreement, and to involve themselves more in conversations (Rogelburg, O’Connor \& Bachiochi, 1996). Pearce \& Ravlin (1987) have gone so far as to suggest that "within-group positional or leadership status should not be formally accorded. Instead, the organization should allow an informal leader or 'captain' to emerge with time." As is typical in the literature, however, no consideration is given to the effects across differing task types.

Some concern may result from using the terms "emergent leader" and "elected leader" interchangeably. In the current study, a limited amount of time was available for the "emergence" process to proceed, potentially disallowing a true opportunity for one team member to completely demonstrate those behaviors which would qualify them as truly emergent. As a result, the team members, when asked to elect their leader, may have been basing their judgments upon an expected extrapolation of the limited perceptions of the leader, general impressions of the leader, or implicit match with personal leadership schemas. Although precedence has been set in the literature to assume that a leader 
elected by his or her team must have emerged (Hollander, 1992), the focus of the current study is to investigate responses to the process of allowing a group to elect a leader (providing a legitimacy base for the leader) versus having one appointed to a group, not to whether the leader was actually emergent or not. The leader in all likelihood may have demonstrated some emergent qualities, and the group's prior knowledge of the restrictive timeframe may have accelerated the emergence process. For the sake of developing the theory and the hypotheses, an assumption is made that the elected leaders displayed typical emergent qualities, thus allowing for the use of the elected leaders as appointed leaders in the other task condition (based on self-monitoring). The leader assignment manipulation was solely based on the groups' responses to the process by which they obtained a leader, and as a result the condition in which the group selected its own leader will be referred to as "elected" and not "emergent".

With these findings and considerations in mind, the group effectiveness outcomes are expected to be more positive for an elected leader condition (where the leader is perceived to have demonstrated emergent characteristics, despite the limited time for the emergence process to proceed) than for an assigned leader condition.

Hypothesis 2a) Groups with elected leaders will be associated with higher performance scores than will groups with assigned leaders. 
Hypothesis 2b) Groups with elected leaders will be associated with higher scores on quality of interpersonal processes and efficiency ratings than will groups with assigned leaders.

Hypothesis 2c) Groups with elected leaders will be associated with higher ratings of satisfaction with the group, its output, and support for the leader than will groups with assigned leaders.

\section{Interaction Effects}

The interaction of the main effects (task type and leader assignment process) is an area that has been totally ignored by previous research. While emergent leadership has been shown to be stable across situations (Zacarro, Foti and Kenny, 1991), perhaps the demands of the task will dictate what leadership assignment process is ideal. For example, perhaps an elected leader (having demonstrated even limited emergent behaviors in order to be elected) is better suited than an assigned leader for tasks high in interdependence, due to the high degree of social interaction. Fry, Kerr and Lee (1986) suggested that, "coordination by standardization, i.e. establishment of bureaucratic rules and routines, is appropriate for low interdependence tasks, but high interdependence requires coordination through mutual adjustments and feedback," which is necessary because the uncertainty inherent in these tasks requires information for task accomplishment to be gathered and processed during the task execution. Considering that these different task conditions may be maximized by specific leadership strategies, it is 
important to know whether or not the leader assignment process introduces perceptual elements making the leader-task contingency more or less effective.

Seers, Petty \& Cashman (1995) made an important contribution to the understanding of task and leader assignment. In groups with an elected leader, the most significant positive increases for team member exchange were for groups with highly interdependent tasks. The largest decrease in exchange quality was found in groups with the lowest level of interdependence. Although findings regarding the exchange quality for groups with assigned leaders across differing levels of interdependence were not mentioned, some insight has been provided as to the contingent nature of the leader-task relationship. Armed with the legitimacy of the election process and with the perceived inherent characteristics of an emergent leader (e.g. provides rewarding interaction, expresses positive supportive behaviors, is perceived as having prototypical leadership qualities), the elected leader is more suited for tasks requiring relational interaction, coordination, and flexible behavioral opportunities.

In support of this proposition, both Bass (1990) and Hackman and Walton (1986) suggested that task ability may not even be the most important factor when looking for a group leader. Although ability is most often used to appoint a leader, these researchers emphasize the importance of taking the degree of task interdependence into account. Bass cites a Kabanoff and O'Brien (1979) study that showed a leader's task competence was irrelevant to group productivity in collaborative task situations. In such a condition, greater emphasis should be placed on the leader's socio-emotional functioning. Likewise, 
Hackman and Walton (1986) suggest that for collaborative teams, a leader's group monitoring and action skills may be more critical than subject matter expertise.

As mentioned earlier, emergent leaders are perceived as more democratic, relationshipfocused, and considerate. Tjosvold (1982) also found that in cooperative situations for difficult tasks, group members perceived their leaders to be more supportive than those in competitive (lower task interdependence) situations. These characteristics fall under what Bass (1990) and Stewart and Manz (1996) describe as the "participative leadership cluster" (reflecting behaviors often attributed to emergent leaders), whereas leaders demonstrating more production-oriented, directive, and structure-initiating behaviors (or perceived behaviors) are described by the "autocratic leadership cluster." Participative leadership would be most appropriate for tasks requiring extensive cooperation, suggests Bass 1990), and a hierarchical status difference between superior and subordinate would be more effective in low interdependence tasks.

This argument supports the research regarding the channels of interaction and communication that group members use during a task. Van de Ven et al. (1976) investigated the use of certain coordination mechanisms across different levels of task interdependence. The findings indicated that with tasks involving high (team) levels of interdependence, group members were likely to use horizontal mechanisms for communication and interaction (i.e. non-hierarchical channels, informal meetings). Conversely, in low interdependence tasks, members used vertical mechanisms (i.e. hierarchical channels, across status-level meetings). The requirements of a high 
interdependence task may support the group members' desire to interact with a leader who is seen as more like the group members themselves. The election process provides the other members of the group with the opportunity to perceive the leader who emerged (or was "left standing" after all other contenders were eliminated) as closer (less vertical) to being "one of them" than an appointed leader.

Typically, high interdependence tasks are less structured, more interactive, and require creative problem solving. Vroom and Yetton's Normative Decision Model suggests that when a task is structured (which is often the case in a low interdependence task) and the leader has the support of subordinates, the less time-consuming autocratic leadership methods can be utilized (Paulus, 1983). The status associated with an appointed leader has been found to stimulate productivity in jobs where problem solving was not required (low task interdependence), whereas the presence of a less "vertical" leader (like an elected leader) has enhanced idea generation and problem solution (Doyle, 1971). With this in mind, it would be expected that the restrictions inherent in the task will determine the optimal contingency for leader assignment. In the more unstructured (high interdependent) situation, a leader needs to be perceived as less vertical and as possessing the qualities that will facilitate the relation-oriented, supportive, flexible nature of the interaction. In contrast, when the situation provides a structured, prescribed method for work flow (low interdependence), the vertical channel offered by an appointed, high status leader would best facilitate efficient group operations. 
Although it is expected that certain types of individuals (i.e. high self monitors) will emerge as leaders in both high and low task interdependence situations, their optimal match is expected to be in high interdependence situations. Here, the group members' positive leader perceptions (reflected by their election decision) will more clearly be in line with the typical emergent, "participative," and supportive behaviors, as well as with the coordination requirements inherent in the task itself. In low interdependence situations, the group performance and member perceptions may be optimized by an appointed (assigned) leader. In this type of task, even if the appointed leader would have been elected and been perceived as emergent (i.e. a high self-monitor), the vertical status associated with being appointed will be more in line with the restricted social requirements of the task.

Thus, the present research demonstrates an opportunity for significant interaction. The literature suggests that team member exchange is significantly greater for high interdependence tasks (when a leader is elected) and that different levels of interdependence may define the level of ability or relational skills which are needed for group effectiveness. Furthermore, elected leaders may have trait-based and legitimacybased tools which best compliment the coordination requirements found in high interdependence task situations, in which group members seek a leader who is more like themselves (less vertical). Such tools may be less critical when tasks are low in interdependence; appointed leadership may better compliment structured tasks requiring 
less problem solving and idea generation. The more optimal the leader assignmentinterdependence match, the more effective the group is expected to be.

Hypothesis $3 a$

1.) In conditions of high task interdependence, groups with elected leaders will be associated with higher performance scores than groups with assigned leaders.

2.) In low task interdependence conditions, groups with assigned leaders will be associated with higher performance scores than groups with elected leaders. Hypothesis $3 b$

1.) In high task interdependence conditions, groups with elected leaders will be associated with higher scores on quality of interpersonal processes and efficiency ratings than groups with assigned leaders.

2.) In low task interdependence conditions, groups with assigned leaders will be associated with higher scores on quality of interpersonal processes and efficiency ratings than groups with elected leaders.

Hypothesis $3 c$

1.) In high task interdependence conditions, groups with elected leaders will be associated with higher ratings of satisfaction with the group, its outputs, and support for the leader than groups with assigned leaders. 
2.) In low task interdependence conditions, groups with assigned leaders will be associated with higher ratings of satisfaction with the group, its output, and support for the leader than groups with elected leaders.

\section{Method}

\section{Subjects}

One hundred forty-eight male undergraduate psychology students from a large state university were randomly assigned to 42 four-person groups (with some subjects returning as appointed leaders). Participants received extra credit for their participation. A power analysis was conducted post hoc to evaluate the number of groups that would be needed for significant effects. Based on guidelines established by Cohen and Cohen (1983) for conducting power analyses, an alpha level (acceptable amount of Type I error) was set at $\alpha=.05$, and an acceptable power level (1- $\beta$, or the probability of rejecting the null hypothesis) was set at .80 . The final variable, effect size, proved to be a challenge. The existing empirical literature relating to the main effects of task interdependence and leader assignment tended to either not report effect sizes or lacked the dependent variables of interest in the current study. Only two studies (Saavedra, Early, and Van Dyne, 1993; DeMatteo, Dobbins, Myers, and Facteau, 1996) were useable, suggesting the use of a "small" effect size (set at .20, in accordance with Cohen and Cohen, 1983). The resulting sample size required for significance is 187 groups. For 
the purpose of consideration, a "medium" effect size of .40 (with power still set at .80 and $\alpha=.05$ ) requires only 46 groups.

Although more groups would have been preferred in order to increase power, time restrictions and difficulty in generating subject participation prevented this from occurring. Extensive effort was expended to recruit a larger number of participants, but competition with other studies requiring a large number of subjects undermined these efforts.

\section{Interdependence Manipulations}

A high (team level) interdependence and low (pooled) interdependence tasks were used. Considering that the tasks were different for each condition, comparison across tasks required that the performance measures (quantity and quality) be standardized to zscores. This prevented performance comparison across interdependence conditions (considering both conditions would have means of zero and standard deviations of one), but it still allowed for the of the interaction hypothesis to be tested (representing the leader assignment/interdependence contingency). In order to evaluate whether the two tasks were conceptually similar enough for such a comparison, an investigation of the performance distributions for the different tasks showed that the scores were similarly distributed. The other ratings (perceived efficiency, interpersonal climate, and satisfaction with the group, its group outputs, and its leader) were scored on a 1-5 point scale, with the lower number representing a more favorable response. All comparisons were conducted at the group level of analysis. 
High interdependence task: This task demanded that the group members use information to make decisions about job placement based on employee profiles (See Appendix A). Consensus was required, and objective quality measures were possible to obtain, as there was an optimal solution to the task (see "Measures" section). This task was unstructured with regard to work flow, required high levels of coordination and interpersonal interaction, and was ecologically valid. The group was responsible for defining its own roles, and no established sequence of sub-task performance was present.

Low interdependence task: This task required that group members manufacture a number of products and was designed to reflect the pooled level of interdependence (See Appendix B). There were specific sub-task roles, which were to be performed individually by each group member (including the leader). Objective evaluation of group output, quality, and quantity was again possible, as each product was required to meet a certain standard, and the number of completed products was easily counted. The goal of the task was to maximize profit, which was accomplished primarily by producing products which met the quality criteria.

\section{Design}

The study used a 2 X 2 design, with method of leader assignment (elected/emergent and appointed) and level of task interdependence (high and low) as the independent variables. Along with the objective group performance scores, survey responses were used to measure the outcome variables of interest for comparison across the four conditions. 
The elected leader condition was performed first, so that the leader who was perceived at having emerged (was elected by the group) was available to serve as the appointed leader for the other leader assignment condition. To eliminate any learning effects, the emergent leaders were assigned to groups in the opposite interdependence condition. For example, if subject $\mathrm{X}$ emerged as the leader of his group in the high interdependence condition, he was assigned as the leader for a group in the low interdependence task. The elected leaders were the only subjects to participate more than once; the other three group members in the appointed leader condition were new to the study.

\section{Leader Assignment Manipulations:}

Elected Condition: No leader was designated at the start of the task. After the initial practice session, the team members were asked to reach a consensus and elect a team leader who they felt "would best lead the group and optimize the group's performance in a similar but more difficult version of the task". The group was given a $3 \mathrm{X} 5$ card and two minutes in order to elect its leader. No specific instructions were given as to how the election process was to be performed. After the card was returned to the experimenter with the leader's name, the role requirements of the leader and the other group members were provided.

Appointed Condition: The group had a leader appointed by the experimenter at the very beginning of the task. No justification was given for the selection of this person, although in reality the person selected was an individual who had been elected (perceived to have emerged) as a leader in the other task and leader assignment elected condition. 
Explicit instructions existed for the experimenter to make the assignment look as random as possible. This was done in order to minimize the possibility of the followers feeling that the assignment was based on some reasonable information (held by the experimenter), thus providing the assigned leader with a type of legitimacy that might detract from the manipulation.

\section{Dependent Variables}

Performance Scores reflected the quantity and/or quality of the group output. For the high interdependence (job placement) task, the final score reflected the degree to which the groups decisions matched the optimal solution for the number of evaluations completed. The raw score was based on how many of the 10 employees were placed in the correct job position, and a percentage was calculated, thus providing a measure of the quality of the group output. For the low interdependence (production) task, performance was based on the amount of profit generated by the group. In order for the group to sell its completed products, the items were required to meet standards. For this reason, the profit generated by the group was a reflection of both quantity and quality of the products. The actual performance measure was based on the amount of money the group generated, minus the expenses (material costs) used to produce the products.

\section{Rating of Perceived Quality of Interpersonal Processes was measured by three}

items based on Saavedra et al.'s (1993) intragroup conflict scale: “There was a lot of tension among people in our group" [reverse scored], "Most people in our group got along with one another," and "Given the way group members performed their roles, I 
often felt frustrated" [reverse scored]. These items were drawn from a larger scale used by Saavedra et al. with an $\alpha=.92$ (for the complete scale). The reason the complete scale was not used for this (and some of the following) measures is that the original scales included additional questions which were not applicable to the focus of the current study or to the tasks being used. Reliability analysis was therefore conducted on the revised scales used to establish the modified coefficient alpha levels (addressed in more detail in the "Results" section). Both measures of this scale were rated on a 5-point Likert scale in which $1=$ strongly agree and $5=$ strongly disagree.

$\underline{\text { Rating of perceived group efficiency }}$ was based on three items also adapted from a larger scale of Saavedra et al. (1993) (complete scale $\alpha=.82$ ): “Our group was highly imaginative in thinking about new or better ways to perform the task", "At times it seemed as if our group was headed in the wrong direction- that is, our approach to the task was not quite what was needed" [reverse scored], and "Our group developed a good strategy for doing the task". Again, all items were scored on a 5-point Likert scale.

Rating of satisfaction with the group and group outputs was based on two items from Rogelberg et al.'s (1996) larger interpersonal climate subscale (complete scale $\alpha=$ .80) :"I wouldn't mind working with the members of my group on another similar project" and "I liked everyone in my group", and two output-related items ("I am satisfied with the strategy our group adopted to accomplish its goal" and "Our group could have performed better -that is, the quality of the work which we as a group 
presented as the final product was not what it should have been"[reverse scored]. The response format was the same 5-point Likert scale.

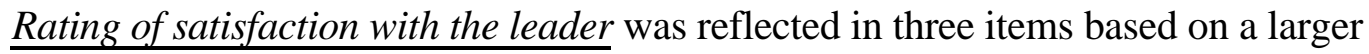
scale (complete scale $\alpha=.81$ ) from DeMatteo, Dobbins, Myers and Facteau's (1996) "Satisfaction with the leader" and "Leadership effectiveness" sub-scales. Items included were, "How do you feel abut your leader on this task?" (anchored with $1=$ extremely satisfied, 5 = extremely dissatisfied), "Overall, how much did the leader contribute to the effectiveness of the group?" (anchored $1=$ very much, $3=$ none), and "If you were to perform a different group task, would you prefer to keep your current leader or select a new group member to be leader?" (anchored on a 3-point scale with $1=$ keep the current leader, $2=$ it would make no difference, or $3=$ select a different group member as the new leader).

$\underline{\text { Manipulation Checks }}$

Three questions were asked to assess the effectiveness and perception of the interdependence and leader assignment manipulations. Subjects responded to:

1. Which description best reflects the instructions which your group was given for the final session of your task?

1. Each person has a specific role, and is responsible for working independently to accomplish his part of the total task

\section{All group members must work together to reach consensus on the optimal solution.}

To what extent do the following statements reflect the type of interaction in which your group engaged? (1= extreme $2=$ substantial $3=$ =moderate $4=$ very little $5=$ =none) 
2. There were no specific roles, and the members HAD to work together to perform the task.

3. Group members were able (and likely) to perform the task without being affected by other group members.

The leader assignment manipulation question asked, "How was the leader determined for your group?: $1=$ election, 2 = assigned."

Confounding Variables

In order to identify possible confounds which may have influenced the dependent variables, several confounding variables were selected and introduced into the questionnaire. Specifically, three questions addressed the degree to which the subjects found the task enjoyable, the extent to which they found the task difficult, and the extent to which they had had prior experience with similar tasks. These measures were used as covariates of the independent variables (see the "Results" section).

In order to explore further the possible relation in the data, the standard deviation for each dependent variable was calculated for each cell, showing the variation across groups within each condition (cell). An ANOVA was performed to investigate the difference in group variability across cells. The results (shown in Table 1) demonstrate that significant differences in mean cell variation were present in the Task Interdependence conditions for Perceived Group Efficiency (High Interdependence groups having less agreement) and Satisfaction with Group Outputs (Low Interdependence groups having less agreement). For the Leader Assignment manipulation, Quality of Interpersonal Processes demonstrated significant differences in 
mean variance across conditions such that emergent leader groups were in less agreement on their response for that variable.

Insert Table 1 about here

\section{Procedure}

Subjects were placed into groups of four in a room isolated from any other groups. Instructions were read to both task conditions, and groups were told that after a 15 minute initial task, a second, more difficult task would begin. For those groups in the assigned leader condition, the appointed leader was identified after the task instructions were read; in the elected leader condition, groups were told (after the practice period) to elect a group leader.

High interdependence task: Job Placement Task

Team members performed a fifteen minute practice task (on very simple sample profiles) in order to become familiar with the task. In the assigned leader condition, the leader was designated before the practice session began, while in the elected condition, the team was allowed to progress through the practice session without a leader (allowing the emergence process to progress). In both conditions, no group-member roles were defined, typical in team level interdependence tasks. Upon completion of the practice session, the "leaderless" group was asked to elect a leader. The groups then began the actual task session, which lasted 30 minutes (10 minutes to work individually, 20 minutes to work in 
group), and required the group members to reach consensus on the optimal solution. Instructions and scoring procedures were identical for both assigned and elected leader conditions.

Low interdependence task: Manufacturing task

Team members performed a fifteen minute practice task (producing very simple objects) in order to become familiar with the task. This practice session was composed of a ten minute planning period and a five minute performance period. In the assigned leader condition, the leader was designated before the practice session began, and group member roles were defined. In the elected condition, the team was allowed to progress through the practice session without a leader (allowing the emergence process to develop). Because no formal roles were defined, group interaction to facilitate leader emergence and election was allowed. After election of the leader, however, the roles were clarified for all group members, as is typical in low-level interdependence task.

The roles were structured in a pooled interaction format, so that each individual (aside from the leader) would be responsible for the manufacturing and quality control of entire products. Upon completion of the initial/practice session, the "leaderless" group was asked to elect a leader. The groups then began the actual task session, which lasted 30 minutes (10 minutes of planning, 20 minutes of production) and required that individuals work separately on their respective portion of the task. Instructions and scoring procedures were identical for both assigned and elected leader conditions. 
After the performance periods (in both conditions) were completed, the subjects were administered the surveys that assessed the perceived effectiveness and potential confounding variables. Groups' performance scores were determined by the profit (manufacturing task) generated by the group or by the job placement scores (relative to the optimal assignment solution).

\section{Results}

Individual responses to the survey items were combined into scale scores (once reliability for the items was established), and then the scale scores were then aggregated to reflect average group responses for each scale. The ANOVA tests, for main effects and interaction for the manipulation check items and for potential confounding variables, were

Insert Table 2 about here

all analyzed at the group level. The point-biserial correlations (shown in Table 1) present the relations between the scales and the independent variables. In particular, Interdependence (Low/High) was negatively related to Perceived Group Efficiency and Satisfaction with Group Output. It is important to remember that smaller responses to the scale questions (closer to 1 than 5) are more favorable. Therefore, the responses to Perceived Group Efficiency and Satisfaction with the Group were more favorable 
(smaller) in the high interdependence condition. The correlations among many of the scales were also significant.

Significant correlations were also observed (Table 2) between the level of interdependence (Low/High) and the responses to the confounding variables (Enjoyment, Experience, Difficulty), with subjects finding the low interdependence task both more difficult and more enjoyable. Subjects also indicated that they were more likely to have had prior experience in tasks similar to the high interdependence (job placement) task.

The Leader Assignment variable demonstrated non-significant relationships to all dependent variables such that groups with emergent leaders were consistently rated more favorably across the scales. Leader assignment was also associated with slightly higher (non-significant) levels of performance.

Expected relationships emerged between the perceptual responses and Group Performance, with more favorable perceptual ratings (closer to 1) being associated with higher levels of performance. Likewise, as groups perform more poorly, the members ratings of the group processes suffer. The remaining intercorrelations (among the scales themselves) reflect the expected pattern of positive relationships. More favorable ratings in one area are related to more favorable rating in another area, and less favorable ratings on one scale relate to less favorable responses in other scales. 


\section{Manipulation Check Items}

The manipulation check items in the questionnaire satisfactorily confirmed the subjects' perception of the experimental manipulations. For the leader assignment question ("How was the leader for your group determined?’), subject responses significantly corresponded to the appropriate assignment condition $(\underline{M}=2.0$ versus $1.47 ; \underline{F}=72.414$, $\mathrm{p}<.01)$. The task interdependence manipulation check presented a significant challenge, both in pilot testing and in the actual experimental condition. The subjects' responses to the three questions (during pilot testing) indicated a misperception as to exactly how they were interpreting the questions. As a result, the questions were modified (as listed in this document), but only one of the three questions ("Which description best reflects the instructions which your group was given for the final session of your task?") demonstrated what was perceived to be a consistent understanding of the question of

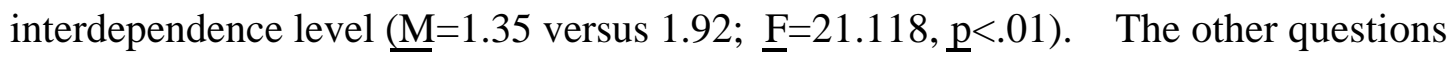
("There were no specific roles, and the members HAD to work together to perform the task" and "Group members were able (and likely) to perform the task without being affected by other group members") did not generate significant differences in responses $(\underline{F}=.822, \underline{p}=n s$ and $\underline{F}=1.164, \underline{p}=n s$, respectively), indicating again what may well be a misperception by the subjects regarding the terms "work together" and "being affected". Considering the significant difference associated with the first question (which was arguably, the best item to tap the manipulated variable) and given confidence in the actual manipulation of the level of task interdependence (based on the clearly defined levels of 
interdependence in the tasks), I feel the results obtained are satisfactory for concluding the presence of that the manipulation was successful.

\section{Confounding Variables}

Three potentially confounding variables were identified a priori (experience with task, enjoyment of task, and perceived difficulty of task), and were measured in the questionnaire. These items were because two separate and very different tasks were being used in the study. To make comparisons across tasks, these variables needed to be controlled so as to better understand the subjects' responses to the unique tasks. The measures were aggregated at the group level, and t-tests were conducted for the two main effect conditions. Despite the significant correlations between these three variable means and Low/High Interdependence, the t-test comparison of the confounding variables for groups in high and low interdependence tasks yielded no significant differences in any of the variables. Similarly, for groups in both assigned and emergent leader conditions, no significant mean differences were observed for any of the confounding variables. As a result, it can be concluded that experience, enjoyment, and perceived level of difficulty were not significant contributors to the variance between the groups in the main effect conditions. 


\section{Scale Reliability}

The reliabilities of the abbreviated scales described above were also evaluated. These analyses were performed at the group level, by aggregating the responses of the group members (non-leaders) for each item within the respective scale. The reason for this aggregation was to obtain responses for entire groups (the focus of this study) on each item in order to capture the responses to the manipulations from the group as a whole. The items comprising each scale are listed in Table 3 . The reliability analyses produced the following results:

The Quality of Interpersonal Processes scale was originally composed of three items: "There was a lot of tension among people in our group", "Given the way group members performed their roles, I often felt frustrated (reverse scored)", and "Most people in our group got along with one another." Due to an initially unsatisfactory alpha level, the latter item was dropped from the scale, resulting in an increase in the final coefficient alpha level $(\alpha=.7463)$.

Similarly, Perceived Group Efficiency was initially a three-item scale consisting of "At times it seemed as if our group was headed in the wrong direction- that is, our approach to the task was not quite what was needed", "Our group developed a good strategy for doing the task", and "Our group was highly imaginative in thinking about new or better ways to perform the task". Again, the last item mentioned was dropped in order to increase the coefficient alpha to a satisfactory level. The resulting two-item scale produced an alpha level of $\alpha=.6296$. 
Originally organized as one scale, Satisfaction with the Group and its Output was broken into two separate scales (providing a more satisfactory alpha level than if kept as one scale). Satisfaction with the Group scale remained in tact, with two items: "I wouldn't mind working with the members of my group on another similar project" and "I liked everyone in my group", producing an alpha of $\alpha=.9215$. Likewise, Satisfaction with Group Output retained both items in the scale: "I am satisfied with the strategy our group adopted to accomplish its goal" and "Our group could have performed better- that is, the quality of the work which we as a group presented as the final product was not what it should have been" (reverse scored), resulting in an $\alpha=.725$.

Finally, Support for the Leader retained all three of its items and produced an alpha of $\alpha=.846$. The three items were "How (satisfied) do you feel about your leader?", "Overall, how much did the leader contribute to the effectiveness of the group?", and "If you were to perform a different group task, would you prefer to keep your current leader or select a new group member to be leader, or would it not matter?".

Considering that the scale items in this study were a subset of existing scales (because not all the items from the original scales applied to the study or to the types of tasks being performed), it is not surprising that the alpha coefficients for the scales would have changed from earlier reported research. However, the resulting alpha coefficients (Table 3) are considered reasonable and acceptable for the use of these scales in the analysis. 


\section{Tests of Hypotheses}

The mean values for each dependent variable were calculated so that comparisons could be made across cells and across levels of manipulation for the independent variables (Table 4).

Insert Table 4 about here

One point to note concerns the extremely small mean value for the Performance variable in the "Total" column. Because each task had a unique scoring system, comparison could only be accomplished by standardizing the performance scores based on the mean and standard deviation of the groups in that task. For this reason, both levels of interdependence exhibit a mean of approximately zero and a standard deviation of 1.0.

Analyses of Variance were then conducted on these means to determine if any main effect or significant interaction were present. The results are listed in Table 5.

Insert Table 5 about here 


\section{Main Effect for Interdependence}

A higher level of interdependence was expected to foster a more interpersonally rewarding and favorable environment for performance. The results suggested that this expectation was partially supported.

Hypothesis 1a predicted that higher levels of task interdependence would be associated with more favorable ratings of Quality of Interpersonal Processes and more favorable ratings of Perceived Group Efficiency. Only Perceived Group Efficiency was significant $\left(\underline{F}=6.885, \underline{p}^{<.05}\right)$, and demonstrated the difference in the predicted direction. Although not significant, Quality of Interpersonal Processes $(\underline{F}=3.646, \underline{p}=.06)$ also demonstrated the predicted trend, with higher interdependence tasks being rated more favorably. Considering that only Perceived Group Efficiency is significantly higher in the High Interdependence condition, hypothesis 1a remains partially supported.

Hypothesis $1 \mathrm{~b}$ posited that high task interdependence would be associated with higher ratings of Satisfaction with the Group, Satisfaction with Group Outputs, and Support for the Leader. Satisfaction with Group Output was significant $(\underline{F}=7.69, \underline{p}<.01)$ in the predicted direction, providing partial support for hypothesis $1 \mathrm{~b}$.

\section{Main Effect for Leader Assignment}

This study attempted to explore the impact of the simple but potentially critical leader assignment strategy in small groups. Appointing a leader versus having the group elect a leader was expected to have some repercussion on the dynamics of the group, 
particularly on group perceptions. The results were all in the expected direction, but no significant difference in these variables were observed between the two leader assignment conditions. Therefore, hypothesis 2 was not supported.

\section{$\underline{\text { Interaction Effects }}$}

Hypothesis 3 stated that the appropriate interdependence-leader assignment interaction would optimize the dependent variable outcomes. The results of the ANOVA and the actual cell means were available to investigate each hypothesized interaction. However, these interactions were not significant. Despite the main effects present in Hypothesis 1, no interaction effect emerge to support the expected interdependence-leader assignment contingency. Thus, Hypothesis 3 was unsupported.

\section{Discussion}

The present study investigated the potential impact of leader assignment strategies (having a leader appointed by someone outside the group versus having the group elect their own leader) on followers' performance outcomes a interpersonal and perceptual outcomes. Leadership in work groups has received much attention in both the literature and in applied settings, but the method by which someone comes to the position of leadership has often been assumed to be unimportant. By investigating the implications of using one assignment method over another, across different types of ecologically valid tasks, the problems of this oversight could be addressed. 


\section{Task Interdependence}

Pooled and team level interdependence tasks were used to demonstrate two very different levels to which group members must rely on each other for successful performance of the tasks. Based on the literature, the less structured, more interpersonal qualities associated with the High Interdependence task were expected to result in more favorable outcomes across both leader assignment conditions. The results significantly confirmed this only for the Perceived Group Efficiency and Satisfaction with Group Output scales. A possible reason for the non -significant results may be found in the nature of the assigned tasks. In particular, the High Interdependence (Job Placement) task required that consensus be reached, with the result that an individual's inputs might have been discounted or sacrificed for the good of the team. In contrast, the Low Interdependence task required each person to contribute individually, thus preventing potentially poor performers from receiving any negative group pressures. This type of situation may have potentially impacted responses on the Satisfaction with the Group, Quality of Interpersonal Processes, and even Support for the Leader.

An additional potential concern relates to the actual difference in behaviors of the leaders in the two different tasks. The hypothesis was based on the very different interpersonal requirements of high and low interdependence tasks (as demonstrated in previous literature such as Zacarro, Foti, and Kenny, 1991, where tasks similar to the ones in this study were shown to require different leadership styles), but in order to perform both tasks, perhaps some level of initiating structure and some level of 
consideration were required. As a result of the behavioral requirements of the tasks not being orthogonal, the leader's behavior may have been similar across task conditions to result in the non-significant responses to the dependent variables. An extension of this research might evaluate any differences in leader behaviors across the specific modification of the task conditions in this study, especially if emergent leaders are used (where self-monitoring would result in changing behavior to match the requirements of the situation). Perhaps some element of the task design (unique to this study) introduced a requirement for a more balanced use of consideration and initiating structure behaviors from the leader.

\section{Leader Assignment}

The nonsignificance of results for the leader assignment factor was disappointing. Perhaps some confounding factor was present to such a degree that the manipulation was interpreted similarly across conditions (at a deeper level than whether the leader was appointed or elected, as was measured by the manipulation check). Several potential reasons why this manipulation did not have the intended effect are plausible.

First, there might have been a perception by the followers in the groups that the leader assignment was not random. Although the experimenter went to lengths to give no indication that the appointed leader was predetermined, there may have been some consistent impression formed across groups that this was not the case. In this respect, such a perception might constitute justification for the leader selection, thus providing a 
level of legitimacy for the appointed leader which would equal that obtained by an elected leader. Such a perception would explain why groups responded to the scales similarly in both appointed and elected conditions.

The actual election process used by the groups may have introduced some error variance within the election condition, compromising the results. For example, if one of the group members volunteered to be leader, the group responses might have been very different than if the group nominated someone. Secret ballots versus "public" votes may have been other election techniques that could have compromised the clarity of the manipulation. The group did have to reach consensus on the leader elected, but by having some inconsistency in the election method, it may have impacted the potency of the manipulation.

Perhaps more significant findings regarding leader assignment versus leader emergence would have been possible in task situations in which the outcome for the group was considered meaningful (such as organizational survival, a bonus in salary, or the individual keeping his or her job). This study intentionally designed the tasks to eliminate performance feedback and rewards, but for the sake of generalizing the findings to an organizational setting, such motivators are often in place and may be quite salient. Based on the present results, it is possible that as motivators become more valued, the group will respond more favorably to a leader that is elected by the group.

Finally, the amount of time the groups had to interact might have been a factor limiting the results. Allowing more time for the groups to interact in the initial session as 
well as in the actual task might have enhanced or changed the level of interaction or the responses to the manipulations. For example, a longer initial session, especially in the elected leader condition, might have allowed more opportunity for the team members to legitimize the elected leader, thus feeling more supportive and expressing that support through better performance. The legitimacy base from which such a leader operates, and the support afforded him or her by the other group members, might have facilitated better team interaction, and thereby led to the favorable outcomes posited in this study.

Interaction of Task Interdependence and Leader Assignment

No significant results were found for the interaction of the two independent variables, suggesting that an optimal leader assignment/task interdependence match did not exist for any of the dependent variables. Some possible factors contributing to these results relate to time, the assumptions typically made about emergent leaders, group size, and power of the study.

The restricted amount of time the groups were able to work together may represent a confounding factor for the interaction effect. The limited time of the initial task session (where the leader could have "emerged") may have been so short as to eliminate the legitimacy base and "leader buy-in" by the followers, thus undermining any of the potential benefits expected from the proposed optimal assignment/ interdependence match. If the followers felt that there was not significant time to assure that the individual they elected was the type of leader who would have emerged (or been 
the "last one standing"), they may have performed similarly no matter what task interdependence requirements were present.

In addition, the non-significant results may be a reflection of a moderating factor associated with perceptions of emergent leaders. The literature overwhelmingly assumes only positive outcomes being associated with emergent leaders. It might be worthwhile, however, to examine potential circumstances where an emergent leader (or the perception of one) is not beneficial (dare I say there is a "dark side" to emergent leadership) to group effectiveness. For example, groups may ascribe a different level of legitimacy, perhaps even distrust, to a group member who demonstrates emergent characteristics, but only in situations where the task is novel or when the group members are not familiar with each other. Perhaps some element of the design of this study introduced one of these potentially negative catalysts into the process, thereby causing subjects in elected leader groups to respond to the manipulation in a similar manner to the appointed leader groups, across both tasks.

Also, where this study used only four person groups, investigating the currently proposed relationships with different group sizes might provide useful information for organizations which employ larger teams. Finally, the number of groups per cell were very small ( $\mathrm{N}=10$ to 12$)$, possibly restricting the power of the study. The issue of low power was a concern throughout the study (especially considering the small effect sizes implied by the literature), but was unavoidable due to time constraints and subject participation challenges. Ideally, by increasing the number of groups used in each cell, 
there is reason to suspect that the encouraging trends mentioned earlier may in fact become significant.

\section{Future Research Opportunities}

One main caution regarding these findings has to do with generalizability. As was mentioned earlier, the tasks in this study were designed to offer no feedback on performance and no real reward for better performance (even low performers and members of low performing groups still received their extra credit point). Adding rewards or feedback (which can be perceived as a type of reward, especially if positive), however, can quickly muddy the waters regarding what factors were driving any observed outcomes, due to the issue of "Complex Interdependence" (Saavedra, Early and Van Dyne, 1993). Basically, Complex Interdependence refers to the match between the level of task interdependence (individual-level being low, and group-level being high) and the level of the reward or feedback (individual or group based). Saavedra et al. (1993) found that optimal outcomes arise from a match between low interdependence-individual feedback/rewards or a match between high interdependence-group feedback/rewards. An extension of the current study would be to introduce individual or group level feedback and rewards across both interdependence and leader assignment conditions. In this way, more insight might be gained as to possible moderators (leader assignment) for the outcomes found by Saavedra, Early and Van Dyne (1993), allowing organizations to better understand the implications of incentives given to teams for performance. In 
addition, investigating additional levels of task interdependence (sequential, for example) might offer further insights to the present relationships.

On the positive side, the laboratory environment for this study was useful for controlling certain variables and eliminating the confounds typically seen in organizations (political power struggles, seniority, past experience, etc.). However, a well-designed field study using members of an organization in realistic work-related tasks might provide a very different and more generalizable source of information. Such a study would also come closer to addressing the aforementioned issue of restricted time (a proposed concern in the current study). Colleagues who have prior "history" or perform together over an extended period of time, might more deeply respond to elected or assigned leaders in their group. While the current study was far removed from a "real" working organizational environment, it was nonetheless a first step toward understanding how work groups respond to leader assignment across different tasks.

Another obvious and important extension of this research would be with femaleonly groups and mixed-gender groups. Mixed-gender group outcomes would be critical for generalizability into the increasingly more diverse work groups seen in organizations today. One issue to resolve in mixed-gender groups, however, is that of perceived preferential or merit-based selection of the leader (DeMatteo, Dobbins, Myers and Facteau, 1996). Perception of preferential treatment (e.g. resulting from affirmative action) might significantly impact the group members' support for the leader, and perhaps the group effectiveness. 
Every organization, no matter how small, needs leadership to perform its task. Countless empirical studies and practitioner resources have been produced to identify and optimize the effects of the leader, but far too often, little thought has been given to the implications that result from deciding who selects the leader. This study has addressed that issue and has hopefully opened the door for more consideration to be given to this decision. 


\section{References}

Baird, John E. \& Weinberg, Sanford B. (1981). Group Communication: The Essence of Synergy ( $2^{\text {nd }}$ ed.). Dubuque, IO: Wm. C. Brown Company Publishers.

Bass, B. M. (1990). Bass and Stodgill's Handbook of Leadership ( $3^{\text {rd }}$ ed.). New York: Free Press.

Ben-Yoav, O., Hollander, E. P., \& Carnevale, P. (1983). Leader legitimacy, leaderfollower interaction, and follower's ratings of the leader. Journal of Social Psychology, $\underline{121}, 111-115$.

Bettenhausen, Kenneth L. (1991). Five years of group research: What have we learned and what needs to be addressed. Journal of Management, 17(2), 345-381.

Cheng, Joseph (1983). Interdependence and coordination in organizations: A rolesystem analysis. Academy of Management Journal, 26(1), 156-162.

Cohen, Jacob and Cohen, Patricia (1983). Applied Multiple Regression/Correlation Analysis for the Behavioral Sciences ( $2^{\text {nd }}$ ed.). Hillsdale, NJ: Lawrence Erlbaum Associates.

Counselman, Eleanor (1991). Leadership in a long-term leaderless women's group. Small Group Research, 22(2), 240-257.

Crawnshaw, S. \& Ellis, R. (1991). A process investigation of self-monitoring and leader emergence. Small Group Research, 22(4), 403-420.

DeMatteo, J., Dobbins, G., Myers, S., \& Facteau, C. (1996). Evaluations of leadership in preferential and merit-based leader selection situations. Leadership Quarterly, 7(1), 41-62.

DeSouza, G. \& Klein, H. (1995). Emergent leadership in the group goal setting process. $\underline{\text { Small Group Research, 26(4), 475-496. }}$

Doyle, Wayne J. (1971). Effects of achieved status of leader on productivity of groups. Administrative Science Quarterly, 16, 40-50.

Eagly, A. \& Karau, S. (1991). Gender and the emergence of leaders: A meta-analysis. Journal of Personality and Social Psychology, 60(5), 685-710. 
Fisher, Kimball (1993). Leading Self-Directed Work Teams. New York: McGraw-Hill.

Fry, L., Kerr, S., \& Lee, C. (1986). Effects of different leader behaviors under different levels of task interdependence. Human Relations, 39(12), 1067-1082.

Garland, H. \& Beard, J. (1979). Relationship between self-monitoring and leader emergence across two task situations. Journal of Applied Psychology, 64(1), 72-76.

Goodman (1986). Impact of task and technology on group performance. In Paul S.

Goodman (Ed.), Designing Effective Work Groups. San Francisco: Jossey Bass.

Goodman, P. S., Ravlin, E., \& Argote, L. (1986). Current thinking about groups:

Setting the stage for new ideas. In Paul S. Goodman (Ed.), Designing Effective Work Groups. San Francisco: Jossey Bass.

Gully, S., Devine, D., \& Whitney, D. (1995). A meta-analysis of cohesion and performance: Effects of level of analysis and task interdependence. Small Group Research, 26(4), 497-520.

Hackman, J. R. (1990). Groups That Work (and Those That Don't): Creating Conditions for Effective Teamwork. San Francisco: Jossey-Bass.

Hackman, J. R. \& Walton, R. (1986). Leading groups in organizations. In Paul S. Goodman (Ed.), Designing Effective Work Groups. San Francisco: Jossey Bass.

Hegstrom, Jane \& Griffith, W.I. (1992). Dominance, sex, and leader emergence. Sex

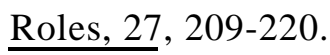

Hollander, E.P. (1978). Leadership Dynamics: A Practical Guide to Effective $\underline{\text { Relationships. New York: Free Press/Macmillan. }}$

Hughes, R., Ginnett, R., \& Curphy, G. (1993). Leadership: Enhancing the Lessons of Experience. Boston: Irwin. 
Johnson, D., Johnson, R., Oritz, A., \& Stanne, M. (1991). The impact of positive goal and resource interdependence on achievement, interaction, and attitudes. Journal of General Psychology, 118(4), 341-347.

Knutson, T. \& Holdridge, E. (1975). Orientation behavior, leadership, and consensus: A possible functional relationship. Speech Monographs, 42(2), 107-114.

Laiken, Marilyn (1994). The myth of the self-managing team. Organization Development Journal, 12(2), 29-34.

Lord, R., DeVader, C., \& Alliger, G. (1986). A meta-analysis of the relation between personality traits and leadership perceptions: An application of validity generalization procedures. Journal of Applied Psychology, 71(3), 402-410.

Manz, Charles \& Sims, Henry (1987). Leading workers to lead themselves: The external leadership of self-managing work teams. Administrative Science Quarterly, 32, 106128.

McGrath, J. E. (1984). Groups: Interaction and Performance. Englewood Cliffs, NJ: Prentice-Hall.

Paulus, Paul B.(1983). Basic Group Processes. New York: Springer-Verlag.

Pearce, J. \& Ravlin, E. (1987). The design and activation of self-regulating work groups. Human Relations, 40(11), 751-782.

Rogelberg, S., O’Connor, G., \& Bachiochi, P. (1996). Leadership emergence in teams without assigned leaders. Paper presented at the annual meeting of The Society for Industrial and Organizational Psychology, San Diego, CA.

Saavedra, R., Early, P., \& Van Dyne, L. (1993). Complex interdependence in taskperforming groups. Journal of Applied Psychology, 78(1), 61-72.

Salancik, G. \& Pfeffer, J. (1977). A social information processing approach to job attitudes and task design. Administrative Science Quarterly, 23, 224-253. 
Seers, A., Petty, M., \& Cashman, J.(1995). Team-member exchange under team and traditional management. Group \& Organization Management, 20(1), 18-38.

Shaw, M. E. (1981). Group Dynamics (3 ${ }^{\text {rd }}$ ed.). New York: McGraw-Hill.

Shea, Gregory P. \& Guzzo, Richard A. (1987). Groups as human resources. Research in Personnel and Human Resources Management, 5, 323-356.

Shonk, James (1992). Team-Based Organizations: Developing a Successful Team Environment. Homewood, IL: Business One Irwin.

Snyder, M. (1987). Public Appearances, Private Realities: The Psychology of Selfmonitoring. New York: W.H. Freeman.

Stewart, G. \& Manz, C. (1996). Leadership for self-managing work teams: A theoretical integration. Paper presented at the annual conference of The Society for Industrial and Organizational Psychology, Nashville, TN.

Taylor, T., Friedman, D., \& Couture, D. (1987). Operating without supervisors: An experiment. Organizational Dynamics, 26-38.

Terborg, J., Castore, C., \& DeNinno, J. (1975). A longitudinal investigation of the impact of group composition on group performance and cohesion. Journal of Personality and Social Psychology, 34(5), 782-790.

Thompson, James D. (1967). Organizations in Action. New York: McGraw-Hill.

Tjosvold, Dean (1982). Effects of cooperative and competitive interdependence and task complexity on subordinates' productivity, perception of leader, and group development. Canadian Journal of Behavioral Science/ Review of Canadian Science Compositions, 14(1), 24-34.

Tjosvold, Dean (1991). Leading the Team Organization: How to Create an Enduring Competitive Advantage. New York: Lexington Books. 
Tuckman, B. (1965). Developmental sequence in small groups. Psychological Bulletin, $\underline{63,} 384-399$.

Wageman, Ruth (1995). Interdependence and group effectiveness. Administrative Science Quarterly, 40, 145-180.

Watson, W. \& Behnke, R. (1990). Group identification, independence, and selfmonitoring characteristics as predictors of leaderless group discussion performance. Journal of Applied Social Psychology, 10, 1423-1431.

Van de Ven, A., Delbecq, A., \& Koening, R. (1976). Determinants of coordination modes within organizations. American Sociological Review, 41, 322-338.

Zacarro, S., Foti, R., \& Kenny, D. (1991). Self-monitoring and trait-based variance in leadership: An investigation of leader flexibility across multiple group situations. Journal of Applied Psychology, 76,(2), 308-315. 
APPENDIX A:

Instructions for Job Placement Task (High Interdependence) 


\section{Instructions for Job Placement Task (High Interdependence)}

Situation: You work for a small arms ammunition manufacturer. The company has expanded and it has hired ten new employees to fill ten new jobs. You are a member of a newly formed Placement Team whose job it is to assign new hires to jobs (each job must have an employee).

Many types of information are often used to assist with the placement process. Three of the most common types of information include:

from

1.) Job preference information (i.e., an employee's preferred job) collected

each person being placed.

2.) Psychological tests results that are used to predict employee performance

on

each job under consideration.

hobbies, $\quad$ and Major Personality Characteristics.

The goal of your group is to assign the ten new employees to ten jobs while attempting to simultaneously meet both the needs of the organization to get the work done and the needs of the individual employee to do the work they enjoy. Attached, you will find the information needed to make the assignments.

\section{Description of Information Pages}

Job Title Page: The first page contains the job title and brief job description for every job that must be assigned an employee.

Employee information pages: After the job title page, there are ten pages, each describing one of the employees to be assigned a job. This information should be considered when assigning employees to jobs. Each page contains the following information:

- Employee name

- Employee age

- Job preferences : each employee has chosen three jobs to which he/she would prefer to be assigned. For example, Chris Jennings' (i.e., the employee on the first sheet for the actual real session) first choice is to be the Magazine Supervisor. His second choice is to be the Chief Inspector. Finally, his third choice is to be the Primer Charger. - Job Rankings: Based on the results of psychological testing, each employee has been ranked against the other 10 employees in terms of predicted performance on all 10 jobs. That is, for each job title, all 10 employees have been ranked from 1, the employee predicted to do the job best, to 10, the employee predicted to be the worst employee on the job. On the Job Title Page, each job title has a number (e.g., Job 1 is Primer Charger). Only the job number appears for the job ranking information. For example, for job 1 (Primer Charger), Chris Jennings is predicted to be the 8th best employee. For job 2 (Ammunition Assembly Laborer), Chris Jennings is predicted to be the 10th best (i.e., the worst) employee.

- Interests \& Hobbies

- Major Personality Characteristics 


\section{Directions:}

A fifteen minute initial session will take place to better familiarize you with the process. The employee information during this first session is only for that session, and should not be used when considering the applicants during the second session. During this first session, you will meet in your group (although in the second session, you will first work alone to make your placement decisions) to reach some consensus regarding the employees. Please keep in mind that there is a correct placement solution to this exercise.

For the second session, you are instructed to come to the group portion of the meeting (session) having already made your decision as to which employees to assign to each job. You will have a total of 10 minutes to individually make your placement decisions. After the ten minutes, you will get together as a group and make the final placement decisions on all 10 employees. You will have 20 minutes to complete this task (in the group), and consensus must be reached.

Appointed leader condition: Identify the leader before the trial session begins> Elected Leader condition: Have the group elect the leader between the two sessions> 


\section{APPENDIX B:}

\section{Instructions for Manufacturing Task (Low Interdependence)}




\section{Instructions for Manufacturing Task (Low Interdependence)}

You are a business organization which manufactures the products displayed in the schematic diagrams in your packet. In this exercise, you will be purchasing raw materials, making the products, and selling them back to the buyer. You will be provided with an itemized list of supply costs and selling prices. All transactions will be made with either the supplier or the buyer.

You will be manufacturing two products during the first session of the exercise (robots and boats), and three products during the second session (jeeps, barges, and lifeguard stands). You have been provided with the assembly instructions for each of the products. The Lego components you will need are small blocks, large blocks, and specialty blocks (these parts are illustrated on a sheet included with the illustrated assembly instructions).

You will construct products in two separate sessions. The component parts will vary in cost from session to session, as will the products themselves. The selling prices will also vary, and some products may not be salable during some sessions. You will be provided with a price list and information about the amount of time allotted for each session. Your company will also receive $\$ 10,000$ in start-up funds. You need to keep track of your funds, and not spend more than you have.

Those in the emergent leader condition for session 1 [to promote interaction for emergence process] will receive the instructions: "How you go about the assembly, what roles you play, and how you organize the company is entirely up to you." Appointed leaders groups (for both sessions) and emergent leader groups (after having elected their leader prior to session 2) will receive the instructions: "In order to properly perform this task, there are certain roles which must be filled. For example, the team will need a leader whose job it is to participate in the task, and optimize group performance. The leader will be responsible for purchasing the materials, selling the materials, keeping track of money, and keeping time. The other group members will be responsible for manufacturing and quality checking their finished products. The group members will manufacture complete products individually (each person tries to make as many products as possible: NO ASSEMBLY LINES!), and pass them on to the leader for resale. Each group member will have a specific role: one will make jeeps, one will make barges, and one will make lifeguard stands. The members will work independently of each other to perform the task.

Before beginning the first exercise, you will have 10 minutes to organize yourselves. In the initial session your group will have 5 minutes to perform the task. In the second session, 
you will have a 10 minute planning period followed by a 20 minute production period. In this exercise, it is important that you keep in mind the following points:

1. Assembly instructions must be followed EXACTLY for the products to be salable. Products which do not match the model will not be bought by the buyer.

2. No component parts may be bought and no products may be sold after the session. However, only the costs and prices for that session will be in effect.

3. Your group objective is to make as much money as possible. After the final session, only the cash you have on hand will be counted. Remaining parts and/or unsold products will remain as costs and will NOT be considered in the final profit figure.

Assigned Condition: Identify Team Leader before session 1>

Elected Condition: Have group elect leader after session 1> 


\section{APPENDIX C:}

\section{Post Task Questionnaire}




\section{Post-task Questionnaire}

Please answer the following questions according to your own perceptions. Do not try to make answers "match up", just simply CIRCLE the answer that you feel when you read the question.

1. There was a lot of tension among people in our group.

$\begin{array}{ccccc}1 & 2 & 3 & 4 & 5 \\ \text { Strongly Agree } & \text { Somewhat Agree } & \text { Neutral } & \text { Somewhat Disagree } & \text { Strongly Disagree }\end{array}$

2. Most people in our group got along with one another.

$\begin{array}{ccccc}1 & 2 & 3 & 4 & 5 \\ \text { Strongly Agree } & \text { Somewhat Agree } & \text { Neutral } & \text { Somewhat Disagree } & \text { Strongly Disagree }\end{array}$

3. Given the way group members performed their roles, I often felt frustrated.

\begin{tabular}{ccccc}
1 & 2 & 3 & 4 & \multicolumn{2}{l}{5} \\
Strongly Agree & Somewhat Agree & Neutral & Somewhat Disagree & Strongly Disagree
\end{tabular}

4. Our group was highly imaginative in thinking about new or better ways to perform the task.
1
2
3
4
5
Strongly Agree Somewhat Agree
Neutral
Somewhat Disagree Strongly Disagree

5. At times it seemed as if our group was headed in the wrong direction- that is, our approach to the task was not quite what was needed.

$\begin{array}{ccccc}1 & 2 & 3 & 4 & 5 \\ \text { Strongly Agree } & \text { Somewhat Agree } & \text { Neutral } & \text { Somewhat Disagree } & \text { Strongly Disagree }\end{array}$

6. Our group developed a good strategy for doing the task.
1
2
3
4
5
Strongly Agree Somewhat Agree Neutral Somewhat Disagree Strongly Disagree

7. I wouldn't mind working with the members of my group on another similar project.

\begin{tabular}{ccccc}
1 & 2 & 3 & 4 & \multicolumn{2}{c}{5} \\
Strongly Agree & Somewhat Agree & Neutral & Somewhat Disagree & Strongly Disagree
\end{tabular}

8. I liked everyone in my group.
1

$$
2
$$
Strongly Agree
Somewhat Agree
3
4
5
Neutral Somewhat Disagree Strongly Disagree
(GO ON TO THE NEXT PAGE >>) 
9. I am satisfied with the strategy our group adopted to accomplish its goal

$\begin{array}{ccccc}1 & 2 & 3 & 4 & 5 \\ \text { Strongly Agree } & \text { Somewhat Agree } & \text { Neutral } & \text { Somewhat Disagree } & \text { Strongly Disagree }\end{array}$

10. Our group could have performed better -that is, the quality of the work which we as a group presented as the final product was not what it should have been.

$\begin{array}{ccccc}1 & 2 & 3 & 4 & 5 \\ \text { Strongly Agree } & \text { Somewhat Agree } & \text { Neutral } & \text { Somewhat Disagree } & \text { Strongly Disagree }\end{array}$

11. I am satisfied with the performance of the leader on this task?

$\begin{array}{ccccc}1 & 2 & 3 & 4 & 5 \\ \text { Strongly Agree } & \text { Somewhat Agree } & \text { Neutral } & \text { Somewhat Disagree } & \text { Strongly Disagree }\end{array}$

12. Overall, the leader contributed substantially to the effectiveness of the group?

$\begin{array}{ccccc}1 & 2 & 3 & 4 & 5 \\ \text { Strongly Agree } & \text { Somewhat Agree } & \text { Neutral } & \text { Somewhat Disagree } & \text { Strongly Disagree }\end{array}$

13. If you were to perform a different group task, would you prefer to keep your current leader or select a new group member to be leader?'(NOTE: New scale)

$\begin{array}{ccc}1 & 2 & 3 \\ \text { Keep Current Leader } & \text { It would make no difference } & \text { Select a different group member }\end{array}$

14. To what extent would you enjoy it if you were asked to perform another session of the task?

$1=$ extreme $2=$ substantial $3=$ moderate $4=$ very little $5=$ none

15. To what extent have you participated in a research experiment/class exercise similar to the task you performed in this current study?

$1=$ extreme $2=$ substantial $3=$ moderate $4=$ very little $5=$ none

16. To what degree did you feel that the task that you performed was difficult?

$1=$ extreme $2=$ =substantial $3=$ =moderate $4=$ very little $5=$ none

17. How was the leader determined for your group?: (circle one)
1
2
Election
Assigned 
18. Which description best reflects the instructions which your group was given for the final session of your task?

1. Each person has a specific role, and is responsible for working independently to accomplish his part of the total task

\section{All group members must work together to reach consensus on the optimal solution.}

Please answer the following questions according to your own perceptions regarding the task in which your group performed in the LAST part of the SECOND SESSION.

19. There were no specific roles, and the members HAD to work together to perform the task.

\begin{tabular}{ccccc}
1 & 2 & 3 & 4 & \multicolumn{1}{l}{5} \\
Strongly Agree & Somewhat Agree & Neutral & Somewhat Disagree & Strongly Disagree
\end{tabular}

20. Group members were able (and likely) to perform the task without being affected by other group members.

\begin{tabular}{ccccc}
1 & 2 & 3 & 4 & \multicolumn{1}{l}{5} \\
Strongly Agree & Somewhat Agree & Neutral & Somewhat Disagree & Strongly Disagree
\end{tabular}




\section{APPENDIX D:}

\section{Tables}

1. $\quad$ ANOVA Results Comparing Standard Deviations

2. Group Level Correlation Matrix (IVs, Performance, Scales, Confounding Variables)

3. Scales Reliabilities

4. Cell and Total Means, Standard Deviations, and Number of Groups

5. ANOVA Results Comparing Means 
Table 1

ANOVA Results Comparing Group Standard Deviations

\begin{tabular}{|c|c|c|c|c|c|c|c|}
\hline \multirow[b]{2}{*}{ Dependant Variable } & \multicolumn{3}{|c|}{$\begin{array}{c}\text { Task Interdependence } \\
\text { (Low / High) }\end{array}$} & \multicolumn{3}{|c|}{$\begin{array}{l}\text { Leader Assignment } \\
\text { (Assign / Emergent) }\end{array}$} & \multirow{2}{*}{$\begin{array}{l}\text { Int } \\
\text { F }\end{array}$} \\
\hline & df & $\mathbf{F}$ & Signif. & df & $\mathbf{F}$ & Signif. & \\
\hline \multicolumn{8}{|l|}{ Performance (Z-score) } \\
\hline Quality of Interpers. Relations & 1 & 0.17 & 0.683 & 1 & 5.5 & $.024^{*}$ & 0 \\
\hline Perceived Grp. Efficiency & 1 & 6.429 & $.015^{\star}$ & 1 & 0.334 & 0.566 & 0.002 \\
\hline Satisf. with Group & 1 & 0.766 & 0.387 & 1 & 2.643 & 0.112 & 0.25 \\
\hline Satisf. with Grp Output & 1 & 6.759 & $.013^{*}$ & 1 & 0.751 & 0.392 & 0.75 \\
\hline Support for Leader & 1 & 0.138 & 0.712 & 1 & 0.352 & 0.557 & 0.034 \\
\hline
\end{tabular}

$* \mathrm{p}<.05$ 


\section{Table 2}

\section{Group Level Correlation Matrix (IVs, Performance, Scales, Confounding Variables)}

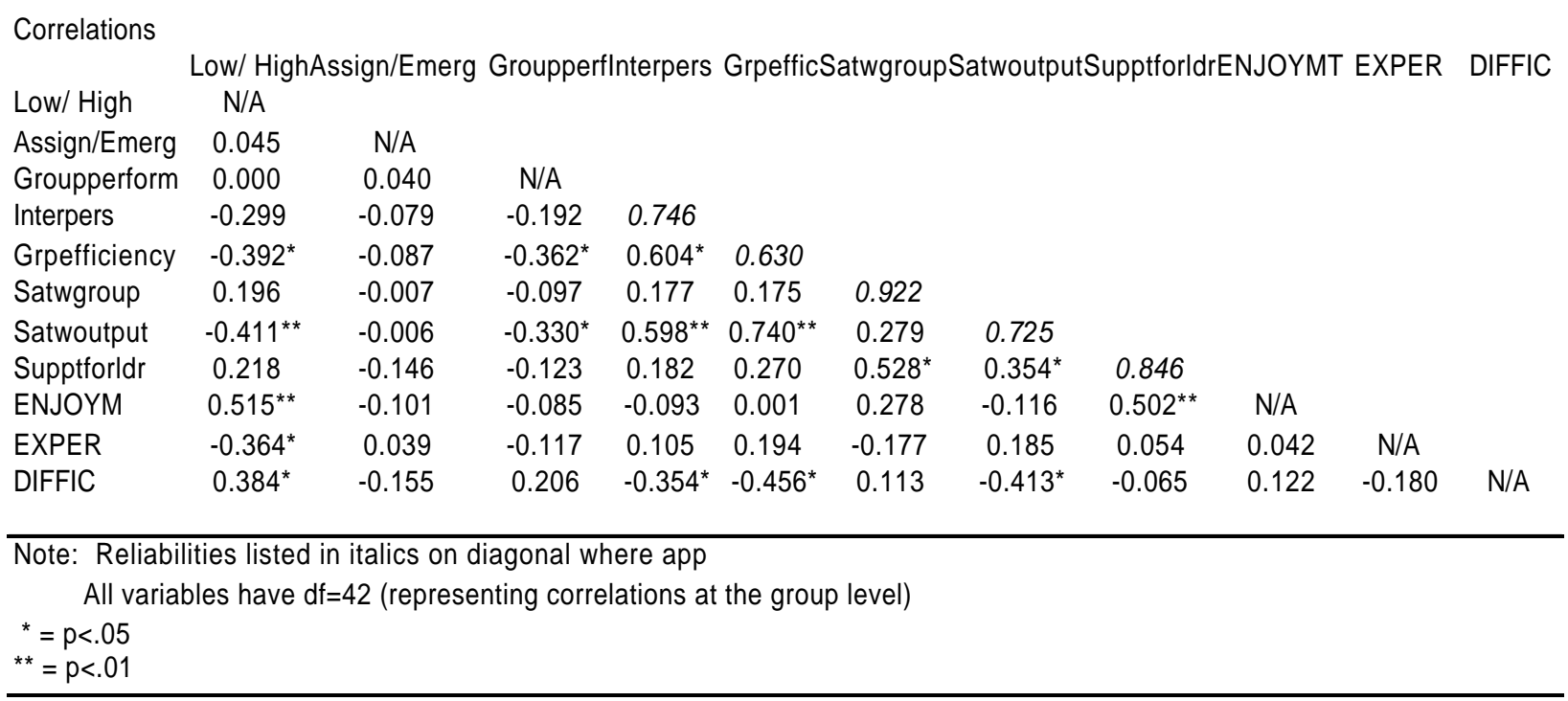


Table 3

Scales Reliabilities

\begin{tabular}{|c|c|c|c|c|}
\hline SCALE & Items & Scale Mean & Scale Variance & Alpha \\
\hline Quality Interpers. Processes & $\begin{array}{l}\text { Tension } \\
\text { Frustrated } \\
\text { (GotAlong) }\end{array}$ & $\begin{array}{c}3.5317 \\
{[4.8730]}\end{array}$ & $\begin{array}{c}1.5396 \\
{[2.0594]}\end{array}$ & $\begin{array}{c}0.7463 \\
{[0.6846]}\end{array}$ \\
\hline Perceived Group Efficiency & $\begin{array}{l}\text { WrongDirect } \\
\text { GoodStrat } \\
\text { (Grplmagin) }\end{array}$ & $\begin{array}{l}4.2143 \\
{[6.5714]}\end{array}$ & $\begin{array}{c}1.7389 \\
{[2.3972]}\end{array}$ & $\begin{array}{l}0.6296 \\
{[0.5497]}\end{array}$ \\
\hline Satisfaction with the Group & $\begin{array}{l}\text { WorkAgain } \\
\text { LikeAll }\end{array}$ & 3.3095 & 0.9019 & 0.9215 \\
\hline Satisfaction with Group Outputs & $\begin{array}{l}\text { StratSatis } \\
\text { PoorQual }\end{array}$ & 4.5238 & 2.0441 & 0.7251 \\
\hline Support for Leader & $\begin{array}{l}\text { SatwLdr } \\
\text { LdrContrib } \\
\text { KeepLeader }\end{array}$ & 5.9524 & 3.4503 & 0.846 \\
\hline
\end{tabular}

Note: (Items in parentheses represent item which were removed from scale)

[Items in brackets represent the scale statistic had that item been left in]

Tension= "There was a lot of tension among the people in our group" (rev. scored)

Frustrat= "Given the way group members performed their roles, I often felt frustrated" (rev. scored)

Got Along= "Most people in our group got along with one another"

WrongDirect $=$ "At times it seemed our group was headed in the wrong direction-that is our approach to the task was not what was needed" (rev. scored)

GoodStrat= "Our group developed a good strategy for doing the task"

GrpImagin= "Our group was highly imaginative in thinking about new or better ways to perform the task"

WorkAgain= "I wouldn't mind working with the members of my group on another similar project"

LikeAll= "I liked everyone in my group"

StratSatis= "I am satisfied with the strategy our group adopted to accomplish the goal"

PoorQual= "Our group could have performed better-that is, the quality of the work which we as a group

persented was not what it should have been" (rev. Scored)

SatwLdr= "How do you feel about your leader?

LdrContrib= "Overall how much did the leader contribute to the effectiveness of the group?"

KeepLdr= "If you were to perform a different group task, wouldd you prefer to keep your current leader or select a new one?" 


\section{Table 4}

\section{Cell and Total Means, Standard Deviations, and Number of Groups}

TOTALS

\begin{tabular}{|c|c|c|c|c|c|c|c|c|}
\hline Dependant Variable & Low & erdepend. & High Int & rdepend. & Low Interd & High Interd & Assig. Ldr & Emerg. Ldr \\
\hline & Assigned & Emergent & Assigned & Emergent & & & & \\
\hline Performance (Z-score) & $\begin{array}{c}0.1219 \\
(0.9686)\end{array}$ & $\begin{array}{l}-0.1219 \\
(1.0677)\end{array}$ & $\begin{array}{l}-0.2038 \\
(0.8351)\end{array}$ & $\begin{array}{c}0.1698 \\
(1.1266)\end{array}$ & $\begin{array}{c}3.123 \mathrm{E}-16 \\
(1.0000)\end{array}$ & $\begin{array}{c}-4.7531 \mathrm{E}-16 \\
(1.0000)\end{array}$ & $\begin{array}{c}-4.0957 \mathrm{E}-0< \\
(0.8959)\end{array}$ & $\begin{array}{c}3.273 \mathrm{E}-02 \\
(1.0842)\end{array}$ \\
\hline & 10 & 10 & 10 & 12 & 20 & 22 & 20 & 22 \\
\hline Quality Interpers. Relations & $\begin{array}{l}1.9833 \\
(0.4611)\end{array}$ & $\begin{array}{l}1.9333 \\
(8.3220)\end{array}$ & $\begin{array}{l}1.6500 \\
(0.5744)\end{array}$ & $\begin{array}{l}1.5417 \\
(0.5371)\end{array}$ & $\begin{array}{l}1.9583 \\
(0.6553)\end{array}$ & $\begin{array}{c}1.5959 \\
(0.5437)\end{array}$ & $\begin{array}{c}1.8167 \\
(0.5350)\end{array}$ & $\begin{array}{c}1.7197 \\
(0.6984)\end{array}$ \\
\hline & 10 & 10 & 10 & 12 & 20 & 22 & 20 & 22 \\
\hline Perceived Grp. Efficiency & $\begin{array}{l}2.4500 \\
(0.3772)\end{array}$ & $\begin{array}{l}2.3000 \\
(7.1060)\end{array}$ & $\begin{array}{l}1.8833 \\
(0.5558)\end{array}$ & $\begin{array}{l}1.8472 \\
(0.7603)\end{array}$ & $\begin{array}{l}2.3750 \\
(0.5590)\end{array}$ & $\begin{array}{l}1.8636 \\
(0.6600)\end{array}$ & $\begin{array}{c}2.1667 \\
(0.5461)\end{array}$ & $\begin{array}{c}2.053 \\
(0.7566)\end{array}$ \\
\hline & 10 & 10 & 10 & 12 & 20 & 22 & 20 & 22 \\
\hline Satisf. with Group & $\begin{array}{c}1.4500 \\
(0.1933) \\
10\end{array}$ & $\begin{array}{c}1.6667 \\
(0.4444) \\
10\end{array}$ & $\begin{array}{c}1.8667 \\
(0.7404) \\
10\end{array}$ & $\begin{array}{c}1.6389 \\
(0.3469) \\
12\end{array}$ & $\begin{array}{c}1.5583 \\
(0.3516) \\
20\end{array}$ & $\begin{array}{c}1.7424 \\
(0.5581) \\
22\end{array}$ & $\begin{array}{c}1.6583 \\
(0.5684) \\
20\end{array}$ & $\begin{array}{c}1.6515 \\
(0.3846) \\
22\end{array}$ \\
\hline Satisf. with Grp Output & $\begin{array}{c}2.5330 \\
(0.5259) \\
10\end{array}$ & $\begin{array}{c}2.6000 \\
(9.4350) \\
10\end{array}$ & $\begin{array}{c}2.0000 \\
(0.6086) \\
10\end{array}$ & $\begin{array}{c}1.9722 \\
(0.5678) \\
12\end{array}$ & $\begin{array}{c}2.5667 \\
(0.7442) \\
20\end{array}$ & $\begin{array}{c}1.9848 \\
(0.5725) \\
22\end{array}$ & $\begin{array}{c}2.2667 \\
(0.6175) \\
20\end{array}$ & $\begin{array}{c}2.2576 \\
(0.8079) \\
22\end{array}$ \\
\hline Support for Leader & $\begin{array}{c}1.8556 \\
(0.5239) \\
10\end{array}$ & $\begin{array}{c}1.8330 \\
(0.6713) \\
10\end{array}$ & $\begin{array}{c}2.3000 \\
(0.6770) \\
10\end{array}$ & $\begin{array}{c}1.9537 \\
(0.5773) \\
12\end{array}$ & $\begin{array}{c}1.8444 \\
(0.5862) \\
20\end{array}$ & $\begin{array}{c}2.1111 \\
(0.3641) \\
22\end{array}$ & $\begin{array}{c}2.0778 \\
(0.6317) \\
20\end{array}$ & $\begin{array}{c}1.899 \\
(0.6095) \\
22\end{array}$ \\
\hline
\end{tabular}

Note: Cell Mean

(Std Dev) 
Table 5

ANOVA Results Comparing Means

\begin{tabular}{lccccccccc} 
& \multicolumn{2}{c}{ Task Interdependence } & \multicolumn{3}{c}{$\begin{array}{c}\text { Leader Assignment } \\
\text { (Assign / Emergent) }\end{array}$} & \multicolumn{2}{c}{ Interaction } \\
Dependent Variable & df & F & Signif. & df & F & Signif. & F & Signif \\
\hline Performance (Z-score) & 1 & 0.003 & 0.957 & 1 & 0.043 & 0.837 & 0.97 & 0.331 \\
Quality of Interpers. Relations & 1 & 3.646 & 0.064 & 1 & 0.174 & 0.679 & 0.024 & 0.879 \\
Perceived Grp. Efficiency & 1 & 6.885 & $.012^{*}$ & 1 & 0.229 & 0.635 & 0.086 & 0.771 \\
Satisf. with Group & 1 & 1.791 & 0.189 & 1 & 0.001 & 0.97 & 2.339 & 0.134 \\
Satisf. with Grp Output & 1 & 7.69 & $.009^{* *}$ & 1 & 0.009 & 0.926 & 0.051 & 0.823 \\
Support for Leader & 1 & 2.209 & 0.145 & 1 & 0.94 & 0.338 & 0.727 & 0.399 \\
& & & & & & & & \\
\hline
\end{tabular}

$* \mathrm{p}<.05$

$* * \mathrm{P}<.01$ 


\section{Kevin J. Basik (Captain, United States Air Force)}

Home Address

13626 Ashley Oaks

San Antonio, TX 78247
Office Address

AF Center For Quality \& Mgt. Innovation Randolph AFB, TX

EDUCATION

Master of Science

July 1997

Industrial / Organizational Psychology

Virginia Polytechnic Institute and State University

Blacksburg, VA

Bachelor of Science

June 1993

Human Factors Engineering

United States Air Force Academy

Colorado Springs, CO

\section{PROFESSIONAL AND RESEARCH EXPERIENCE}

8/95 - PRESENT

7-93- 7-95
Thesis Research

Chairperson: Roseane J. Foti

Virginia Polytechnic Institute and State University

Blacksburg, VA

- Investigated the effects (across different levels of task interdependence) of appointing leaders to workgroups versus letting the group elect their leader.

Air Force Research Coordinator

Navy Personnel Research and Development Center

San Diego, CA

- Managed manpower and performance appraisal research for joint AF-Navy efforts

\section{RELEVANT COURSEWORK}

\section{Content Courses:}

Industrial Psych. (I \& II)

Organizational Psych. I (Motivation)

Organizational Psych, II (Leadership)

Cognitive Psychology

Social Psychology

Personality

\section{Research Methods and Statistics:}

Research Methods

Quantitative Topics for I/O Psych. Multivariate Analysis

Stats for Social Science Research I

Stats for Social Science Research II 